\title{
Growth of Loudness in Listeners with Cochlear Hearing Losses: Recruitment Reconsidered
}

\author{
Søren BuUs, ${ }^{1,2}$ AND Mary Florentine ${ }^{1,3}$ \\ ${ }^{1}$ Institute for Hearing, Speech, and Language, Northeastern University, Boston, MA 02115, USA \\ ${ }^{2}$ Communications and Digital Signal Processing Center, Department of Electrical and Computer Engineering (442 DA), \\ Northeastern University, Boston, MA 02115, USA \\ ${ }^{3}$ Department of Speech-Language Pathology and Audiology (133 FR), Northeastern University, Boston, MA 02115, USA
}

Received: 16 October 2000; Accepted: 3 August 2001; Online publication: 20 December 2001

\begin{abstract}
This article examines how loudness grows with increasing intensity near threshold in five listeners with hearing losses of predominantly cochlear origin. It provides evidence against the pervasive and long-held notion that such listeners show abnormally rapid loudness growth near their elevated thresholds. As in a previous study for listeners with normal hearing, loudness functions near threshold were derived from loudness matches between a pure tone and four- or ten-tone complexes using a simple model of loudness summation. This study assumed that the loudness function had the same form for any component of a complex, but a scale factor that depended on the amount of hearing loss allowed the loudness at threshold to vary with frequency. The best-fitting loudness functions had low-level local exponents [i.e., slopes of the low-level loudness function plotted as $\log$ (loudness) versus $\log$ (intensity)] that were within the normal range. At $0 \mathrm{~dB}$ SL, the average local exponents were 1.26 for the listeners with hearing losses compared with 1.31 for normal listeners, which indicates that loudness near threshold grows at similar rates in normal listeners and listeners with hearing losses. The model also indicated that, on average, the loudness at threshold doubled for every $16 \mathrm{~dB}$ of hearing loss. The increased loudness at threshold, together with somewhat enlarged local exponents around $20 \mathrm{~dB}$ SL, accounts for the nearnormal loudness often obtained for high-SPL tones in
\end{abstract}

Correspondence to: Dr. Søren Buus 9 Tower Drive • Dover, MA 02030. Telephone: (617) 373-5196; fax: (617) 373-5199; email: buus@neu.edu listeners with hearing losses. Such loudness functions are consistent with the steep functions shown by classical data on loudness matches between tones for which thresholds are normal and tones for which thresholds are elevated. Thus, the present data indicate that an abnormally large loudness at an elevated threshold is likely to be a better definition of recruitment than the classical definition of it as an abnormally rapid growth of loudness above an elevated threshold.

Keywords: loudness, cochlear hearing losses, recruitment, threshold, models

\section{INTRODUCTION}

Listeners with cochlear hearing losses cannot hear a low-SPL tone in the frequency range of their hearing loss. However, once the tone is about $30 \mathrm{~dB}$ above threshold, its loudness level is usually reduced by only a fraction of the amount of hearing loss. That is, the level difference between equally loud tones in regions of cochlear hearing loss and in regions of normal hearing almost always decreases as sound level increases. This fact has led to one of the longest-standing "truths" about cochlear hearing losses, i.e., loudness grows abnormally fast as the sound intensity increases above the elevated threshold of a listener with a cochlear hearing loss. Indeed, loudness matches between tones for which the threshold is normal and tones for which the threshold is elevated due to cochlear hearing loss show that maintaining equal 
loudness requires the level of the tone with normal threshold to be raised 2 or $3 \mathrm{~dB}$ for every 1-dB increase in the level of tones within about $30 \mathrm{~dB}$ of the elevated threshold (e.g., Pohlman and Kranz 1924; Fowler 1928; 1936; Steinberg and Gardner 1937; MiskolczyFodor 1960). This result has led numerous authors to conclude that cochlear hearing loss leads to an abnormally rapid growth of loudness in the vicinity of the elevated threshold, i.e., recruitment (Fowler 1937; for review, see Brunt 1994; Moore 1998).

Whereas loudness-matching data show that the loudness level grows more rapidly than normal near threshold in a listener with hearing loss, it does not necessarily follow that loudness grows more rapidly than normal (Allen 1997). Neely and Allen (1997) pointed out that the concept of recruitment as an abnormally rapid growth of loudness is erroneous if one considers the growth of loudness on a linear scale as a function of stimulus intensity, also on a linear scale. They modeled the loudness function for a listener with hearing loss by introducing a level-dependent attenuation, which they argued mimicked the loss of compression resulting from outer-hair-cell dysfunction. Using this hypothetical loudness function, they showed that the derivative of loudness with respect to stimulus intensity, i.e., the mathematical definition of the slope of the loudness function, always was less for the model listener with hearing loss than for a normal listener.

Describing growth of loudness on a linear scale per unit of intensity appears useful for investigating possible relationships between difference limens for intensity and loudness. However, the convention of examining the logarithm of loudness (or linear loudness plotted on a logarithmic scale) as a function of stimulus level in $\mathrm{dB}$ (or, more generally, a logarithmic scale of intensity) is more useful for understanding the perception of amplified sounds. Amplification and any other linear transformation to the stimulus preserves $\mathrm{dB}$ differences between stimuli and-because the loudness function at moderate and high levels is well approximated by a power function of intensityloudness ratios. Accordingly, the remainder of this article considers loudness on a logarithmic scale as a function of the level (in $\mathrm{dB}$ ) of the stimulus. To avoid confusion, the rate of growth of loudness will be described by a power-function approximation to the loudness function over a small range of levels around any level. The power-function approximation may be specified by its exponent, which we call the local exponent because it characterizes the loudness function locally. The local exponent is simply the slope of the loudness function when loudness as a function of stimulus intensity is plotted on logarithmic scales of loudness and intensity. [Note that some authors use exponents that characterize loudness as a function of sound pressure (e.g., Hellman and Zwislocki 1961;
Stevens 1961; Scharf 1978b; Hellman and Meiselman 1993). Such exponents are twice those used throughout this article.]

In normal listeners, loudness for tones well above threshold closely follows a compressive power function of intensity (e.g., Knauss 1937; Stevens 1955; Hellman 1991). That is, the local exponent at high levels is nearly constant over a wide range of levels and is much smaller than unity. As the tone approaches threshold, the local exponent of the loudness function increases (e.g., Fletcher and Munson 1933; Zwislocki and Hellman 1960; Hellman and Zwislocki 1961, 1963; Lochner and Burger 1961; Scharf and Stevens 1961; Zwislocki 1965; Buus et al. 1998). Recent measurements indicate that the loudness function may also be less compressive at high than at moderate levels (Florentine et al. 1996, 1998; Buus et al. 1997, 1999). Mechanical measurements of vibration amplitudes on the basilar membrane show quite similar characteristics. It is close to linear at low levels but becomes very compressive at moderate levels (e.g., Robles et al. 1986; Yates 1990; Ruggero et al. 1997). The midlevel compression results because outer hair cells increase the mechanical gain as the sound level decreases. However, the outer hair cells cannot increase the basilar-membrane gain indefinitely and it appears to be maximal for tones within $15 \mathrm{~dB}$ of threshold. This fact accounts for the nearly linear basilar-membrane response at low levels. The similarity between loudness functions and basilarmembrane input-output functions has led some authors to suggest that relatively simple relationships exist between loudness and vibration amplitude of the basilar membrane (Buus et al. 1997; Schlauch et al. 1998). According to this view, the increase of the local exponent of the normal loudness function near threshold reflects the absence of basilar-membrane compression at low levels.

In cochlear hearing losses, part of the threshold elevation usually can be attributed to damage of the outer hair cells, which reduces the mechanical gain for low-level tones and reduces the compression. This loss of compression is often stated to be consistent with the presence of recruitment in listeners with cochlear hearing losses (e.g., Patuzzi 1993; Moore and Glasberg 1997; Moore 1998). However, in the purported region of abnormally large local exponents (i.e., near threshold) the basilar-membrane response is approximately linear whether the threshold is elevated by cochlear pathology or is normal. To the extent that the growth of loudness reflects the growth of the basilar-membrane response, one might expect that the local exponent of the loudness function near threshold should be similar for normal listeners and listeners with cochlear hearing losses, at least within 10 or $15 \mathrm{~dB}$ of threshold. This notion is contrary to the classical concept of recruitment, but is consistent with reports 
by Hellman and coworkers (Hellman and Zwislocki 1964; Hellman and Meiselman 1990; Hellman 1999). Based on loudness data obtained at levels down to 4 dB SL using a variety of methods, they used extrapolation to estimate the local exponent of the loudness function at threshold in listeners with hearing losses and suggested that it is essentially the same as that obtained for normal listeners.

If loudness grows at a normal rate above a threshold intensity that is elevated by cochlear pathology, how does it catch up to be nearly normal at levels well above threshold? One possible explanation emerges by noting that the classic idea of recruitment as an abnormally large local exponent near threshold implicitly rests on the assumption that the loudness of a tone at threshold is the same (often incorrectly assumed to be zero) whether the threshold is normal or is elevated by cochlear pathology. However, recent data from Buus et al. (1998) show that loudness at threshold exceeds zero, at least in most of their listeners with normal hearing. Although many authors have proposed loudness functions according to which loudness at threshold is zero (for review, see Buus et al. 1998), our finding of nonzero loudness at threshold should hardly be surprising. It agrees with Hellman and Zwislocki's $(1961,1964)$ hypothesis that loudness is proportional to intensity near threshold, which implies that loudness at threshold is not zero, and Zwislocki (1965) has presented convincing theoretical arguments why loudness at threshold ought to exceed zero.

The fact that loudness at threshold is greater than zero opens the possibility that the loudness of a tone at a threshold may vary with frequency (cf. Hellman 1994) and differ across listeners. In other words, the absolute threshold curve is not necessarily an isoloudness contour. It seems possible that the loudness of a tone at a threshold intensity that is elevated by cochlear pathology is greater than the loudness at threshold for a normal listener. According to this hypothesis, the near-normal loudness obtained for high-level tones in listeners with cochlear hearing losses may result because the loudness at their elevated thresholds is abnormally large and not because the local exponent of the loudness function is abnormally large near threshold. [It should be noted that for some listeners, especially those with severe hearing losses, the loudness of tones well above threshold is less than normal, i.e., they show partial recruitment, defined as the loudness level being reduced more than 10 phons at high SPLs (Jerger 1962; for review, see Brunt 1994). However, even in listeners with partial recruitment, the loudness of high-level tones is a much larger fraction of the normal loudness than is the loudness of a tone whose SPL is near their elevated thresholds.]

As shown in Figure 1, abnormally large loudness at

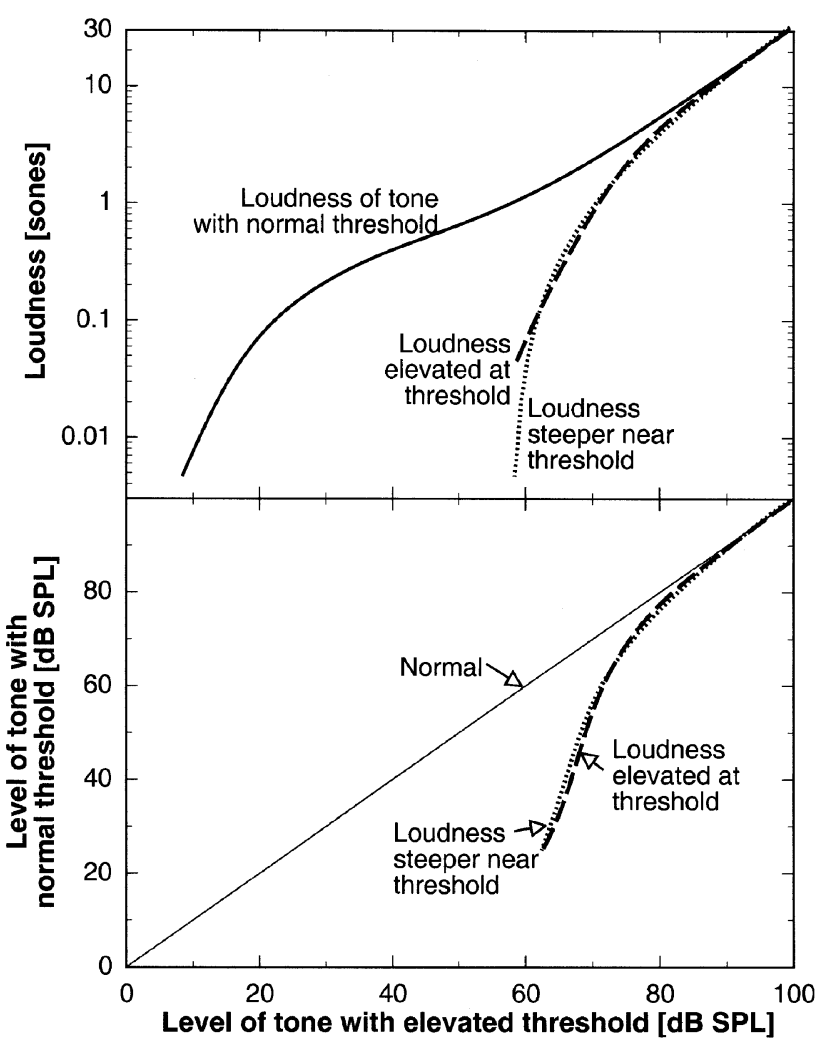

FIG. 1. The top panel illustrates two possible forms of loudness growth in listeners with cochlear hearing losses. The solid line shows the normal loudness function. In accord with recent measurements, it is more compressive (i.e., the local exponent is smaller) at moderate levels than at high levels (Buus et al. 1998; Florentine et al. 1998). The dotted and dashed lines show two hypothetical loudness functions for a listener with a 50-dB hearing loss. For illustration, both assume complete recruitment such that they coincide with the normal loudness function at high SPLs. The dotted line follows the classical view of recruitment (Fowler 1937), which holds that loudness growth is abnormally rapid (i.e., the local exponent is abnormally large) above a threshold that is elevated by cochlear pathology. The dashed line shows an alternative loudness function. Near threshold, the local exponent is the same as that for the normal loudness function, but the loudness at low SLs has been scaled to illustrate the idea that loudness at threshold is elevated when the threshold is elevated by a cochlear hearing loss. At moderately low SLs, the local exponent is somewhat larger than normal, which illustrates that outer-haircell dysfunction is likely to reduce the strong midlevel compression obtained for normal listeners. The bottom panel shows loudness matches between tones with normal thresholds and tones with elevated thresholds predicted from the loudness functions in the top panel. The predictions are shown only at and above $4 \mathrm{~dB} \mathrm{SL}$, which is the lowest level at which reliable loudness can be obtained with traditional procedures. The loudness matches are nearly identical whether loudness is assumed to grow abnormally fast above the elevated threshold (dotted line) or to be elevated at the elevated threshold (dashed line).

threshold and abnormally rapid growth of loudness above an elevated threshold both can account for typical loudness matches between tones for which thresholds are elevated and tones for which thresholds are normal when the matches are at levels more than 4 
$\mathrm{dB}$ above threshold - the lowest level at which reliable loudness matches can be obtained with traditional procedures (Hellman and Zwislocki 1961). The top panel shows loudness functions according to the two competing hypotheses and the bottom panel shows loudness matches derived as pairs of levels yielding equal loudness for a normal ear and for an ear with hearing loss according to one or the other loudness function in the top panel. For levels above $4 \mathrm{~dB}$ SL, the loudness matches would be nearly identical whether loudness for listeners with hearing losses is normal at their elevated thresholds and the local exponent is abnormally large within $30 \mathrm{~dB}$ of threshold (classic hypothesis; dotted lines) or loudness starts at a greater-than-normal loudness at the elevated threshold, but the local exponent is normal near threshold (alternative hypothesis; dashed lines). This observation implies that the data from loudness matches do not necessarily favor the classic interpretation that loudness grows abnormally rapidly in listeners with hearing loss. They are equally consistent with a greater-than-normal loudness at threshold in such listeners. In other words, the abnormally rapid growth of loudness level, which Allen (1997) suggested could be an appropriate definition of recruitment, may occur either because the local exponent of the loudness function for listeners with hearing losses is abnormally large, or because the loudness at threshold is elevated when the threshold intensity is elevated by hearing loss. Accordingly, it seems worthwhile to examine how loudness grows near the elevated thresholds of listeners with cochlear hearing losses.

Buus et al. (1998) showed that loudness matches between pure tones and tone complexes provide a highly reliable method for assessing the rate of loudness growth near threshold. The standard error across three repeated loudness matches averaged $2.4 \mathrm{~dB}$ when the tone was varied and $1.6 \mathrm{~dB}$ when the tone complexes were varied, which allowed the local exponent of individual listeners' loudness function at threshold to be determined with a standard error of 10\%-15\%. A similar technique was employed by Fletcher and Munson (1933) to determine the form of the loudness function for normal listeners, but they made few measurements near threshold and did not test listeners with hearing losses. The basic premise for this method is that the loudness scale is additive (Fletcher and Steinberg 1924; Fletcher and Munson 1933; for review, see Allen 1996), which means that a tone complex consisting of $n$ equally loud components ought to be $n$ times as loud as a single component. This should hold as long as the components do not mask one another, which usually is fulfilled when they are near threshold and their frequencies are sufficiently far apart. Accordingly, the level difference between equally loud pure tones and $n$-tone complexes shows directly the increase in level necessary to produce an $n$-fold increase in loudness. The present study employed this technique to assess the local exponent of the loudness functions near the elevated thresholds of listeners with hearing losses of primarily cochlear origin.

\section{METHOD}

The procedure and stimuli were identical to those used in a previous study with normal listeners (Buus et al. 1998).

\section{Stimuli}

Tones at $1600 \mathrm{~Hz}$ were matched in loudness to tone complexes centered near $1600 \mathrm{~Hz}$. The stimulus duration was $500 \mathrm{~ms}$ measured between the half-amplitude points of the 20 -ms raised-cosine rise and fall. To assess the effect of mutual masking among the components and to assess the consistency in the data, measurements were made for four-tone complexes with frequency separations of one, two, four, or six critical bands (Barks; cf. Zwicker 1961; Zwicker and Feldtkeller 1967; Scharf 1970) and for ten-tone complexes with frequency separations of one or two critical bands. To minimize the number of possible component frequencies, the complexes with a 1-Bark frequency separation were centered (on the critical-band-rate scale) at 12 Barks $(1720 \mathrm{~Hz})$ instead of the nominal center frequency of 11.5 Barks $(1600 \mathrm{~Hz})$. Accordingly, the component frequencies were at 17 critical-band centers between 2.5 and 20.5 Barks. The corresponding frequencies are 250, 450, 570, 700, 840, 1000, 1170, 1370, 1600, 1850, 2150, 2500, 2900, 3400, 4000, 4800, and $7000 \mathrm{~Hz}$. Following the procedure used for normal listeners in our previous experiment, all components in a complex had the same sensation level (SL). Note that if our hypothesis is true and loudness at threshold is greater than normal when the threshold is elevated by a cochlear hearing loss, the loudnesses of the equalSL components may vary across frequency when the amount of hearing loss varies with frequency. In addition, equal-SL components well above threshold almost certainly will differ in loudness as indicated by the classical loudness-matching functions discussed in the Introduction. Such differences in the loudness of individual components in a complex make it difficult to estimate local exponents of the loudness function directly from inspection of the loudness-matching data. However, they are easily accounted for by incorporating them into a model that allows the form of the loudness function to be estimated from the loudness matches, as discussed below.

Apart from reliability, the use of tone complexes to 
assess the loudness function near threshold is advantageous because it allows measurement of the loudness for components that are at or even a few $\mathrm{dB}$ below threshold. A tone complex generally will be audible even if the components are a few $\mathrm{dB}$ below their individual thresholds (e.g., Green et al. 1959; Buus et al. 1986; Hicks and Buus 2000). Accordingly, the component level in the fixed complexes usually ranged from about $-3 \mathrm{~dB}$ SL to near $20 \mathrm{~dB}$ SL. The levels of the fixed single tones were chosen individually for each listener and tone complex to approximate the range of loudnesses produced by the complexes.

\section{Apparatus}

A PC-compatible computer with a signal processor (TDT AP2) generated the stimuli through a 16-bit D/ A converter (TDT DD1) with a $50-\mathrm{kHz}$ sample rate. It also sampled the listeners' responses and executed the adaptive procedure. The output of the D/A was attenuated (TDT PA4), lowpass filtered (TDT FT5, $f_{c}=20 \mathrm{kHz}, 135 \mathrm{~dB} /$ octave), attenuated again (TDT PA4), and led to a headphone amplifier (TDT HB6), which fed one earphone of the Sony MDR-V6 headset. The listeners were seated in a sound-attenuating booth. For routine calibration, the output of the headphone amplifier was led to a 16-bit A/D converter (TDT DD1), such that the computer could sample the waveform, calculate its spectrum and RMS voltage, and display the results before each set of matches.

\section{Procedure}

Absolute thresholds. To obtain a reference for setting the SLs, absolute thresholds were measured for each of the 17 component frequencies using an adaptive procedure in a two-interval, two-alternative forcedchoice paradigm. Each trial contained two observation intervals, which were marked by lights. The pause between them was $450 \mathrm{~ms}$. The signal was presented in either the first or the second observation interval with equal a priori probability. The listener's task was to indicate which interval contained the signal by pressing a key on a small computer terminal. Two hundred milliseconds after the listener responded, the correct answer was indicated by a 200-ms light. Following the feedback, the next trial began after a 200-ms delay.

The level of the signal initially was set approximately $15 \mathrm{~dB}$ above the listener's threshold. It decreased following three consecutive correct responses and increased following one incorrect response. The step size was $5 \mathrm{~dB}$ until the second reversal and $2 \mathrm{~dB}$ thereafter. Reversals occurred when the signal level changed from increasing to decreasing or vice versa.
This procedure converges on the signal level yielding 79.4\% correct responses (Levitt 1971).

A single threshold measurement was based on three interleaved adaptive tracks. A track is a series of trials for which the signal level is governed by a single instance of the adaptive algorithm. Thus, the signal level on a given trial (which consists of two observation intervals and one response by the listener) depends only on the listener's response to preceding trials belonging to the same track. Because the tracks were interleaved, trials for other tracks usually intervened between successive trials for any given track. On each trial, the track was selected at random among the tracks that had not yet ended. Each track ended after five reversals. The threshold for one track was calculated as the average signal level at the fourth and fifth reversals and one threshold measurement was taken as the average threshold across the three tracks. At least three such threshold measurements (for a total of at least nine tracks) were obtained for each listener and frequency. The average across all measurements was used as the reference to set the SL of the single tone and the components of the complex in the subsequent experiments. This procedure provides a highly reliable measurement of threshold (Hicks and Buus 2000).

Loudness matches. In the second part of the experiment, each tone complex was matched in loudness to the $1600-\mathrm{Hz}$ tone using an adaptive procedure with a two-alternative forced-choice paradigm. On each trial, a pure tone and a tone complex were presented in random order with a $600-\mathrm{ms}$ interstimulus interval. The listener pressed a key to indicate which was louder. The level of the variable sound initially was set about $10 \mathrm{~dB}$ above the expected equal-loudness level and was adjusted according to a simple up-down procedure (Jesteadt 1980; Florentine et al. 1996). If the listener indicated that the variable sound was the louder one, its level was reduced; otherwise, it was increased. The step size was $5 \mathrm{~dB}$ until the second reversal and 2 $\mathrm{dB}$ thereafter.

To reduce biases that may occur when only a single fixed sound is presented in a series of trials, six to ten interleaved adaptive tracks were used to obtain concurrent loudness matches at three to five levels with both the pure tone and the tone complex varied. On each trial, the track for that trial was selected at random from all tracks that had not yet ended. Each track ended after nine reversals. The equal-loudness level for one track was calculated as the average of the levels at the last four reversals. Three such matches were obtained for each listener and condition. This procedure has been shown to be successful in reducing biases that affect loudness matches with traditional adaptive procedures (Buus et al. 1998). 


\begin{tabular}{|c|c|c|c|c|c|c|c|c|c|c|c|c|c|}
\hline \multicolumn{14}{|c|}{ TABLE 1} \\
\hline \multicolumn{14}{|c|}{ Audiometric data for the five listeners ${ }^{a}$} \\
\hline \multirow[b]{2}{*}{ Listener } & \multirow[b]{2}{*}{ Age } & \multirow[b]{2}{*}{ Ear } & \multicolumn{8}{|c|}{ Audiometric thresholds (dB HL) Frequency $(\mathrm{kHz})$} & \multicolumn{3}{|c|}{ Speech tests } \\
\hline & & & 0.25 & 0.5 & 1 & 1.5 & 2 & 3 & 4 & 8 & $\begin{array}{c}S R T \\
(d B H L)\end{array}$ & $\begin{array}{l}\text { Discrim. } \\
(\% \text { correct) }\end{array}$ & $\begin{array}{c}\text { Level } \\
(d B H L)\end{array}$ \\
\hline \multirow[t]{2}{*}{ L1 } & 46 & $\mathbf{R}$ & 35 & 40 & 50 & & 65 & & 65 & 70 & 45 & 78 & 85 \\
\hline & & $\mathrm{L}$ & 25 & 35 & 45 & & 70 & & 65 & 85 & 45 & 68 & 95 \\
\hline \multirow[t]{2}{*}{ L2 } & 55 & $\mathrm{R}$ & 35 & 35 & 40 & & 30 & & 15 & 20 & 25 & 96 & 75 \\
\hline & & $\mathbf{L}$ & 35 & 35 & 40 & & 35 & & 15 & 15 & 30 & 96 & 75 \\
\hline \multirow[t]{2}{*}{ L3 } & 30 & $\mathrm{R}$ & 10 & 5 & 10 & 20 & 45 & 65 & 70 & 55 & & 92 & 80 \\
\hline & & $\mathbf{L}$ & 15 & 5 & 10 & 15 & 55 & & 65 & 50 & & 92 & 80 \\
\hline \multirow[t]{2}{*}{ L4 } & 50 & $\mathrm{R}$ & 30 & 35 & 50 & & 45 & & 55 & 80 & 42.5 & 88 & 85 \\
\hline & & $\mathbf{L}$ & 40 & 40 & 40 & & 45 & & 50 & 70 & 42.5 & 96 & 85 \\
\hline \multirow[t]{2}{*}{ L5 } & 55 & $\mathbf{R}$ & 55 & 65 & 70 & & 65 & & 75 & 70 & 60 & 74 & 90 \\
\hline & & $\mathrm{L}$ & 60 & 60 & 70 & & 65 & & 70 & 90 & 65 & 86 & 90 \\
\hline
\end{tabular}

${ }^{a}$ Data for the test ear are shown in bold. The first three columns show the listener identifier, age, and ear. The next eight columns show the amount of hearing loss in dB HL (ANSI 1989) at various audiometric frequencies as indicated in the column heading. The final three columns show results of speech tests: The Speech Reception Threshold, the percentage of words recognized, and the level at which the words were presented. Blank cells indicate that the measurement was not performed.

\section{Listeners}

Two female and three male listeners with hearing losses of primarily cochlear origin participated in the experiment. The probable origin of the hearing loss was diagnosed on the basis of a clinical assessment that included a case history, air and bone audiometry, tympanometry, and speech intelligibility. As shown in Table 1, the audiograms encompassed a variety of configurations and the listeners' ages ranged from 30 to 55 years. Data for the test ear are shown in bold. All listeners volunteered to participate in the experiment. They provided full informed consent and were compensated for their services. The experimental protocol and the informed consent form were approved by the Institutional Review Board at Northeastern University.

\section{Derivation of pure-tone loudness functions}

A simple model was used to derive a pure-tone loudness function from all the matches made by an individual listener. It assumes that the loudness function has the same form for all pure tones and follows a modified power function, which is derived from the loudness function proposed by Zwislocki (1965). He proposed that loudness is obtained as the output of a compressive power-function transformation of the total intensity of the signal and an internal noise. The internal noise accounts for absolute threshold. To ensure that loudness is zero if no stimulus is present, he assumed that the listener subtracts the loudness of the internal noise. Accordingly, Zwislocki (1965) suggested that the loudness of a pure tone, $N_{\mathrm{pt}}$, ought to follow the function

$$
N_{\mathrm{pt}}=k^{\prime} \cdot\left[\left(I_{\mathrm{in}}+I_{\mathrm{pt}}\right)^{s \mathrm{hi}}-I_{\mathrm{in}}^{\text {shi }}\right]
$$

where $k^{\prime}$ is an arbitrary scaling factor that can be chosen to make the loudness equal to 1 sone at $40 \mathrm{~dB}$ SPL, $I_{\text {in }}$ is the intensity of the internal noise (measured within a critical band centered on the tone), $I_{\mathrm{pt}}$ is the intensity of the pure tone, and $s_{\mathrm{hi}}$ is the exponent of the compressive power function that is the asymptotic approximation to Eq. (1) when $I_{\mathrm{pt}}$ becomes large. In other words, $s_{\mathrm{hi}}$ is the local exponent of the loudness function at high levels.

Zwislocki (1965) further assumed that threshold corresponded to a fixed signal-to-noise ratio, $s n r_{\text {th }}$, such that the intensity of a tone at threshold would be $I_{\mathrm{th}}=\operatorname{snr}_{\mathrm{th}} \cdot I_{\mathrm{in}}$. Accordingly, Eq. (1) can be rewritten as

$$
\begin{aligned}
N_{\mathrm{pt}} & =k^{\prime} \cdot I_{\mathrm{inh}}^{s \mathrm{sh}} \cdot\left[\left(1+\frac{I_{\mathrm{pt}}}{I_{\mathrm{in}}}\right)^{s \mathrm{hi}}-1\right] \\
& =k \cdot\left[\left(1+s n r_{\mathrm{th}} \cdot \frac{I_{\mathrm{pt}}}{I_{\mathrm{th}}}\right)^{s \mathrm{hi}}-1\right]
\end{aligned}
$$

where $k$ is an arbitrary scale factor $\left(=k^{\prime} \cdot I_{\mathrm{in}}^{\text {shi }}\right)$.

For stimulus intensities well below threshold, Zwislocki's (1965) loudness function approaches a linear function, which means that the local exponent approaches unity. Buus et al. (1998) observed that loudness tended to grow slightly faster than the intensity of a pure tone (i.e., the local exponent tended to be greater than unity) for levels near threshold in normal listeners. Accordingly, they modified Eq. (2) to contain an additional parameter, $s_{\mathrm{l}}$, that allowed the low-level local exponent of the loudness function to vary freely. They calculated the loudness as

$$
N_{\mathrm{pt}}=k \cdot\left[\left(1+\left(\operatorname{sn} r_{\mathrm{th}} \cdot \frac{I_{\mathrm{pt}}}{I_{\mathrm{th}}}\right)^{s_{\mathrm{lo}}}\right)^{s_{\mathrm{hi}} / s_{\mathrm{lo}}}-1\right]
$$

where $s_{\mathrm{l}_{\mathrm{O}}}$ is the exponent of the slightly expansive 
power function that is the asymptotic approximation to Eq. (3) when $I_{\mathrm{pt}}$ is well below threshold. For the purposes of the present experiment, it is important to note that having $s_{\mathrm{lo}}$ as a fitting parameter allows modeling of the loudness functions that would be obtained if loudness were to grow abnormally fast near threshold for the listeners with hearing losses.

To account for the possibility that loudness at threshold may be elevated when the threshold is elevated, the loudness function in Eq. (3) was modified to contain a scale factor that depends on the amount of hearing loss at the frequency of the tone. For the sake of simplicity, it was assumed that the elevation of loudness at threshold follows a power function of the intensity ratio between the normal threshold and the listener's actual threshold for the tone. Accordingly, the loudness of a pure tone for a listener with hearing loss was calculated as

$N_{\mathrm{pt}}=k \cdot\left(\frac{I_{\mathrm{th}}}{I_{\mathrm{th} \_ \text {normal }}}\right)^{s_{\mathrm{HL}}}\left[\left(1+\left(s n r_{\mathrm{th}} \cdot \frac{I_{\mathrm{pt}}}{I_{\mathrm{th}}}\right)^{s_{\mathrm{lo}}}\right)^{s_{\mathrm{hi}} / s_{\mathrm{lo}}}-1\right]$

where $I_{\text {th } \_ \text {normal }}$ is the average (standard) threshold for listeners with normal hearing and $s_{\mathrm{HL}}$ is the exponent of the power function that determines how much a given hearing loss elevates the loudness at threshold. Note that $s_{\mathrm{HL}}$ is a constant and is independent of frequency. Of course, the elevation of loudness at threshold depends on frequency to the extent that the amount of hearing loss varies with frequency.

Finally, it is useful to recast Eq. (4) in terms of the amount of hearing loss, $H L$, and the sensation level of the tone, $S L$. Both $H L$ and $S L$ are given in dB. Because the hearing loss in $\mathrm{dB}$ is defined as $10 \cdot \log$ $\left(I_{\mathrm{th}} / I_{\text {th } \_ \text {normal }}\right)$ and the sensation level is $10 \cdot \log$ $\left(I_{\mathrm{pt}} / I_{\mathrm{th}}\right)$, Eq. (4) can be rewritten as

$N_{\mathrm{pt}}=k \cdot 10^{\mathrm{sLL}(H L / 10)}$.

$$
\left[\left(1+\left(\operatorname{snr}_{\mathrm{th}} \cdot 10^{S L / 10}\right)^{s_{\mathrm{lo}}}\right)^{S_{\mathrm{hi}} / s_{\mathrm{lo}}}-1\right],
$$

where $s_{\mathrm{HL}}, s n r_{\mathrm{th}}, s_{\mathrm{lo}}$, and $s_{\mathrm{hi}}$ are free parameters and $k$ is a scale factor that does not affect the predictions of the model. In this expression, $s_{\mathrm{HL}}$ determines the extent to which the loudness at threshold varies with the amount of hearing loss, $s n r_{\text {th }}$ may be considered the signal-to-noise ratio at threshold [which will be reported as $\left.S N R_{\mathrm{th}}=10 \cdot \log \left(s n r_{\mathrm{th}}\right) \mathrm{dB}\right], s_{\mathrm{lo}}$ is the asymptotic exponent of the loudness function at low levels, and $s_{\mathrm{hi}}$ is the asymptotic exponent at high levels. This function has been shown to provide an excellent description of normal listeners' loudness functions for tones below about $40 \mathrm{~dB}$ SL, provided appropriate parameter values are chosen (Buus et al. 1998). Note that local exponents corresponding to the asymptotic exponents given by the model parameters $s_{\mathrm{lo}}$ and $s_{\mathrm{hi}}$ may not be reached within the range of sound levels used for the experiment.

Because the loudness scale is additive (Fletcher and Steinberg 1924), the loudness $N_{c}$ of a tone complex is obtained as the sum of the loudnesses of the individual components. However, partial masking among the components (i.e., partial overlap of the excitation patterns produced by the individual components) may reduce the loudness contributions of individual components (Fletcher and Munson 1937; Zwicker 1958, 1963; Zwicker and Scharf 1965; Zwicker and Feldtkeller 1967; Allen 1996; Moore et al. 1997). In effect, areas of overlap contribute to the total loudness only once; thus, the loudness contribution for an area of overlap is "lost" for all but one of the overlapping components. As long as one is interested only in the total loudness, it is unimportant whether the "lost" loudness is subtracted from one or the other component. For the present purposes, it is convenient to assume that any loudness that is lost as a result of overlap between the loudest component and some other component is subtracted from the loudness of the less loud component. This ensures that the total loudness calculated for a tone complex never will be less than the loudness of the loudest component. Accordingly, the total loudness of a tone complex, $N_{c}$, can be calculated as

$$
\begin{aligned}
N_{c}=\max \left\{N_{\mathrm{pt}}\left(S L, H L_{i}\right)\right\}+(1-r(\Delta f, S L)) \\
{\left[\sum_{i} N_{\mathrm{pt}}\left(S L, H L_{i}\right)-\max \left\{N_{\mathrm{pt}}\left(S L, H L_{i}\right)\right\}\right] }
\end{aligned}
$$

where $i$ indexes the components of the tone complex, $S L$ is the sensation level of a single component in the complex, $H L_{i}$ is the amount of hearing loss for the $i$ th component, and $r(\Delta f, S L)$ accounts for the loudness reduction that results from partial masking. Similar to the model used for normal listeners (Buus et al. 1998), $r(\Delta f, S L)$ is assumed to be zero (i.e., partial masking did not play a role) for SLs below a breakpoint whose value depended on $\Delta f$ and to increase linearly above the breakpoint. To reduce the number of free parameters, the slope above the breakpoint was the same for all $\Delta$ fs.

This method of adding only some fraction of the component loudnesses to account for partial masking is identical to that used by Buus et al. (1998), but their expression for the summation of partial loudnesses is simpler because they reasonably could assume that the equal-SL components in a complex were equally loud for their normal listeners. It is also similar to the summation method used by Fletcher and Munson (1933), who reduced the loudness contribution of all but the lowest-frequency component by some fraction $1-b_{k}$, which could differ across components. In our formulation, $1-r(\Delta f, S L)$ is equivalent to $b_{k}$, which Fletcher 
and Munson (1933) stated was a function of the frequencies and levels of adjacent components. For equally loud components, they stated that $b_{k}$ was determined only by the loudness level and the frequency separation, measured in terms of distance between the places of maximal excitation on the basilar membrane. This is essentially equivalent to making it a function of SL and frequency separation measured in Barks, at least in normal listeners. For the range of sensation levels used in the present study, Fletcher and Munson (1933) found the best fit to their data when $b_{k}$ decreased approximately linearly with level above some critical level that depended on the frequency separation. This form of loudness reduction due to partial masking is identical to that used in the present study and by Buus et al. (1998). In summary, the method used for summation of component loudnesses and accounting for partial masking is essentially the same as that used by Fletcher and Munson (1933), but the parameters may differ because of differences in the stimuli used.

\section{RESULTS}

Figure 2 shows loudness matches obtained from each of the five listeners. The insets show thresholds measured in the test ear for tones at various frequencies using the adaptive forced-choice procedure. The thick lines show model predictions, which are discussed later. Consider first the data for L1 in the top row. On average, the four-tone complexes with components set to threshold (i.e., $0 \mathrm{~dB}$ SL) match a $1600 \mathrm{~Hz}$ puretone set to about 5.4 dB SL ( \pm a standard error of 0.4 $\mathrm{dB})$. Because the pure tone is well above threshold, it must have a loudness greater than zero. Accordingly, the loudness of the components at threshold also must exceed zero because their individual loudnesses add up to produce a loudness equal to that of the pure tone. This finding is also apparent in the data for the other four listeners with hearing losses. Thus, these data show that loudness at threshold for listeners with cochlear hearing losses exceeds zero, as it does for normal listeners (Buus et al. 1998).

Apart from showing that loudness at threshold is greater than zero, the present data also inform us of how loudness grows as the intensity increases above threshold. The finding that L1 judges four tones at 0 $\mathrm{dB}$ SL to be as loud as one tone at $5.4 \mathrm{~dB}$ SL shows that a 5.4-dB increase in level produces a fourfold increase of the loudness at threshold-assuming that all components of the complex are equally loud. (This assumption is likely to be fulfilled because the amount of hearing loss varies relatively little with frequency for L1. Table 1 indicates that L1's hearing loss is less at 250 and $500 \mathrm{~Hz}$ than at the higher frequencies. However, a detailed comparison of the forced-choice thresholds in the inset of Figure 2 with normal listeners' thresholds obtained using the same procedure and apparatus indicates that L1's hearing loss is between 50 and 65 dB HL for all but the two lowest frequencies used in the present study. The forced-choice thresholds indicate hearing losses of $42 \mathrm{~dB} \mathrm{HL}$ at $250 \mathrm{~Hz}$ and $46 \mathrm{~dB} \mathrm{HL}$ at $450 \mathrm{~Hz}$.) Accordingly, the data for four-tone complexes indicate that the local exponent of L1's loudness function just above threshold (i.e., between 0 and $5.4 \mathrm{~dB}$ $\mathrm{SL})$ is $10 \cdot \log (4) / 5.4=1.12$. The data for the tentone complexes provide a similar estimate. On average, the ten-tone complexes at $0 \mathrm{~dB}$ SL match the pure tone at $9.4 \mathrm{~dB}$ SL $( \pm 1 \mathrm{~dB})$. The corresponding local exponent of the loudness function (midway between 0 and $9.4 \mathrm{~dB}$ SL) is 1.06. For comparison, Buus et al. (1998) found that the local exponent of the loudness function near threshold calculated in the same manner from the average data for five normal listeners was about 1.14. Thus, the data for L1 indicate that loudness grows no faster near her elevated threshold than does loudness near threshold for normal listeners.

It is noteworthy that frequency separation has no consistent effect on L1's loudness matches at low SLs. This indicates that the estimate of the local exponent of the loudness function near threshold is unlikely to be affected by reduced frequency selectivity. If it were, one would expect four-tone complexes with a 1-Bark frequency separation to yield loudness matches different from those obtained with the wider frequency separations.

Similar trends are evident in the raw data for L2. She matched the four-tone complexes with a component level of $0 \mathrm{~dB}$ SL to an average pure-tone level of $4.8 \mathrm{~dB}$ SL. The corresponding local exponent is 1.27. For the ten-tone complexes, the average level of the matching pure tone was 7.5 dB SL, corresponding to a local exponent of 1.33. Again, the estimates from the four- and ten-tone complexes show close agreement and are similar to the local exponent obtained for normal listeners. A close inspection of L2's data provides an indication that the equal-SL components may have differed in loudness. When the component level was $0 \mathrm{~dB}$ SL, L2 judged the four-tone complex with a 6-Bark component separation 2.9 phons softer than the other four-tone complexes. Likewise, she judged the ten-tone complex with a 2-Bark component separation 3.4 phons softer than the ten-tone complex with a 1-Bark component separation. This indicates that loudness at threshold may be less for the extreme (most likely high) frequencies than for the middle frequencies. Because L2 has only a small amount of hearing loss at and above $4 \mathrm{kHz}$, this finding seems consistent with the notion that loudness at threshold may increase with the amount of hearing loss.

The raw data for other listeners are more difficult 


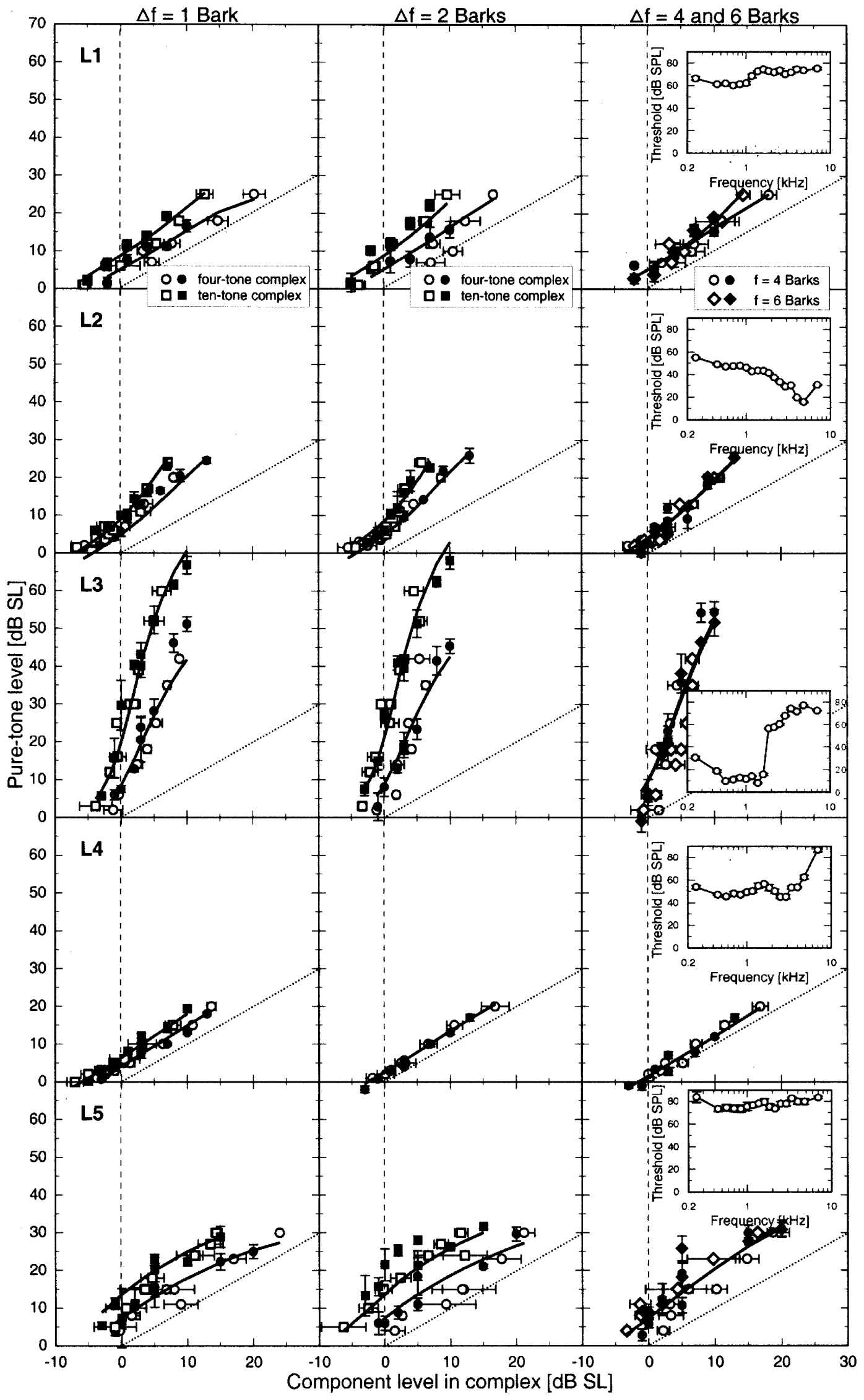


TABLE 2

Parameters of pure-tone loudness functions that provide the best fit to loudness matches between tones and tone complexes ${ }^{a}$

\begin{tabular}{|c|c|c|c|c|c|c|c|c|c|}
\hline \multirow[b]{2}{*}{ Listener } & \multirow[b]{2}{*}{$s_{l o}$} & \multirow[b]{2}{*}{$s_{h i}$} & \multirow{2}{*}{$\begin{array}{l}S N R_{\text {th }} \\
(d B)\end{array}$} & \multirow[b]{2}{*}{$s_{H L}$} & \multicolumn{3}{|c|}{ Local Exponents at SL } & \multirow{2}{*}{$\begin{array}{l}\text { Model error } \\
(d B)\end{array}$} & \multirow{2}{*}{$\begin{array}{c}\text { SE of data } \\
(d B)\end{array}$} \\
\hline & & & & & $O d B$ & $10 \mathrm{~dB}$ & $20 d B$ & & \\
\hline L1 & 1.23 & 0.21 & -10.3 & 0.00 & 1.21 & 0.96 & 0.52 & 2.2 & 1.8 \\
\hline L2 & 1.42 & 0.20 & -4.2 & 0.20 & 1.29 & 0.69 & 0.38 & 2.0 & 1.4 \\
\hline L3 & 2.17 & 0.12 & -1.2 & 0.14 & 1.78 & 0.55 & 0.29 & 5.2 & 2.9 \\
\hline L4 & 1.15 & 0.41 & -8.3 & 0.62 & 1.11 & 0.87 & 0.58 & 0.9 & 1.5 \\
\hline L5 & 1.16 & 0.48 & 0.8 & 0.00 & 0.94 & 0.65 & 0.53 & 3.6 & 2.8 \\
\hline Average & 1.43 & 0.28 & -4.6 & 0.19 & 1.26 & 0.74 & 0.46 & 2.8 & 2.1 \\
\hline SD & 0.43 & 0.15 & 4.7 & 0.26 & 0.32 & 0.17 & 0.12 & 1.6 & 0.7 \\
\hline
\end{tabular}

${ }^{a}$ The parameters are the low-level asymptotic exponent $s_{\mathrm{lo}}$, the high-level asymptotic exponent $s_{\mathrm{hi}}$, the signal-to-noise ratio at threshold, $S N R_{\mathrm{th}}$ (estimated within a critical band around the signal frequency); and the exponent $s_{\mathrm{HL}}$ of the power function that describes the effect of the amount of hearing loss on the loudness at threshold. The next three columns show the local exponents of the loudness functions for each listener at 0,10 , and $20 \mathrm{~dB}$ SL. The next-to-last column shows the rms deviation between the predicted pure-tone levels and the individual listeners' matching data. For comparison, the last column shows the standard error across three repetitions of the loudness matches in which the pure-tone level varied. Averages and standard deviations are shown in the bottom two rows.

to evaluate because the estimates of local exponents differ somewhat across the various tone complexes. However, this should not be taken to indicate that these listeners' loudness matches were inconsistent. The amount of hearing loss varies considerably across the components used for the complexes, which would cause the loudness for the 0 -dB-SL components to vary across frequency if loudness at threshold increases with the amount of hearing loss. Thus, differences among the various complexes may simply reflect that the threshold elevation varies across frequency. If so, the model described in the Methods section should be able to predict the loudness matches from these listeners with less straightforward audiometric configurations.

Indeed, the loudness-matching functions predicted by the model provide an excellent account of the data for all the listeners, as shown by the solid lines in Figure 2. The parameters for the best-fitting pure-tone loudness function and the rms error of the predictions of the matching pure-tone are summarized in Table 2. [The breakpoints for $r(\Delta f, S L)$ were between 0 and $3 \mathrm{~dB}$ SL for $\Delta f=1$ Bark and between 0 and $10 \mathrm{~dB}$ SL for $\Delta f=2$ Barks. For the 4 - and 6-Bark $\Delta f$, the breakpoints usually were above the range of SLs used, i.e., no partial masking was apparent for most listeners with these wide frequency separations and low SLs. The exceptions were breakpoints at $3 \mathrm{~dB}$ SL for L1 and at $0 \mathrm{~dB}$ SL for L5 with the 4-Bark $\Delta f$ and at $5 \mathrm{~dB}$ SL for L5 with the 6-Bark $\Delta f$. The slopes (increase in proportion of loudness loss per $\mathrm{dB}$ above the breakpoint) ranged from 0.019 to 0.048.] As evident from Figure 2 and the rms errors of the predictions (see Table 2), the model provides an excellent fit to the data. The rms errors of the predicted pure-tone levels range from 0.9 to $5.2 \mathrm{~dB}$ and are generally not much larger than the 1.4-2.9-dB standard error calculated across the matches in which the tone varied. Moreover, the puretone loudness functions conformed to expectations based on the SL differences between the components in the various complexes and the equally loud tones as discussed above. For L1, the local exponent of the model loudness function at threshold is 1.21 , which is only slightly larger than the local exponents of 1.06 and 1.12 obtained directly from the loudness-matching data for complexes with a 0-dB-SL component level. For L2, the local exponent of the model loudness function at threshold is 1.29 , which is almost identical
FIG. 2. Loudness matches between tones at $1600 \mathrm{~Hz}$ and four- or ten-tone complexes centered near $1600 \mathrm{~Hz}$ obtained in five listeners with hearing losses of primarily cochlear origin. The sensation level (SL) of the pure tone is plotted as a function of the SL of a single component of equally loud four- (circles and diamonds) or ten-tone complexes (squares). Unfilled symbols show data obtained when the adaptive procedure varied the level of the tone complex and filled symbols show data obtained when the adaptive procedure varied the level of the pure tone. The error bars show plus and minus one standard error of the mean calculated across three repetitions of each loudness match. The solid lines show loudness matches predicted by a simple model of loudness summation (see text). In some cases, the two lines overlap for the four-tone complexes with $\Delta f_{s}$ of 4 and 6 Barks. The vertical dashed lines indicate threshold for the individual components in a tone complex. The thin dotted lines indicate equal SLs for the pure tone and the components of the tone complex. Each row of panels shows data for a different listener. The left panel shows data for a component separation of 1 Bark, the middle panel shows data for a component separation of 2 Barks, and the right panel shows data for four-tone complexes with component separations of 4 and 6 Barks. The insets in the right-hand panels show the listeners' thresholds measured in the test ear at 17 component frequencies between 250 and $7000 \mathrm{~Hz}$ using the adaptive forced-choice procedure. The error bars show plus and minus one standard error calculated across three threshold measurements. It is barely visible for most of the data because the error bar usually is smaller than the symbol; the average standard error of the thresholds is $1.2 \mathrm{~dB}$. 
to the local exponents of 1.27 and 1.33 obtained directly from her data. Altogether, it is clear that the loudness functions derived by the model reflect rather well the loudness matches from which they were derived.

As shown in Table 2, the low-level asymptotic exponents of the loudness functions, $s_{\mathrm{lo}}$, range from 1.15 to 2.17 with an average of 1.43 and $S N R_{\mathrm{th}}$ ranges from -10.3 to $0.8 \mathrm{~dB}$ with an average of $-4.6 \mathrm{~dB}$. These values, which determine the form of the low-level part of the loudness function, are very similar to those for normal listeners, as discussed later. On the other hand, the high-level asymptotic exponents $s_{\text {hi }}$ tend to be larger than normal; they ranged from 0.12 to 0.48 with an average of 0.28 . Finally, the effect of the amount of hearing loss on the loudness at threshold, $s_{\mathrm{HL}}$, indicates that the loudness at threshold generally increases as the amount of hearing loss increases. (It should be noted that the model yielded a best-fitting value of $s_{\mathrm{HL}}$ equal to -0.94 for L5, but $s_{\text {hi }}$ obtained with this fit was far above the range obtained for the other listeners. Because setting $s_{\mathrm{HL}}$ to zero for $\mathrm{L} 5$ yielded a much more reasonable value for $s_{\mathrm{hi}}$ and an rms error that was only slightly larger than that obtained with the best-but unreasonable - fit ( 3.6 vs. $3.2 \mathrm{~dB}$ ), the values obtained with $s_{\mathrm{HL}}$ equal to zero are shown in Table 2.) The average value of $s_{\mathrm{HL}}$ is 0.19 . This value corresponds to a doubling of the loudness at threshold for each 16$\mathrm{dB}$ increase in the amount of hearing loss.

The loudness functions determined from the loudness-matching data are illustrated in Figure 3. The broken lines show loudness functions for the individual listeners calculated according to the parameters in Table 2. For comparison, the solid lines show a normal loudness function. It was constructed by combining the low-SL loudness function obtained by the method used in the present study (Buus et al. 1998) with the loudness function obtained from measurements of temporal integration at high SLs (Florentine et al. 1998). At low SLs, the local exponents of the loudness function for the listeners with hearing losses are very similar to those for normal listeners, but at moderate SLs the local exponents tend to be larger than normal when the threshold is elevated. However, for levels well above threshold, the loudness functions for normal listeners and listeners with hearing losses appear to have similar local exponents when they are compared at equal SPLs. This finding agrees with the near-normal rates of loudness of growth usually obtained for high-level tones in listeners with cochlear hearing losses (e.g., Steinberg and Gardner 1937; Moore 1998). As shown by the X's and the dotted line, the loudness functions for the listeners with hearing losses have been scaled according to the average value of $s_{\mathrm{HL}}$. This scaling increases the loudness at threshold when the threshold is elevated and-perhaps aided by somewhat enlarged local exponents over a restricted range of levels near $20 \mathrm{~dB}$ SL-makes the moderateSL portions of the loudness functions for the listeners with hearing losses approach the normal loudness function when the loudness functions for normal listeners and for listeners with hearing losses are plotted as functions of the SPL.

\section{DISCUSSION}

This section addresses three important issues. The first subsection considers how reduced frequency selectivity, which usually accompanies cochlear hearing losses, might affect the outcome of our measurements. The second subsection compares in some detail the parameters for the loudness functions of the listeners with cochlear hearing losses with those obtained for normal listeners in our previous study. Finally, the third subsection considers the implications of the present data for understanding the perception of loudness by listeners with cochlear hearing losses.

\section{Effects of reduced frequency selectivity}

One basic premise of the present study is that individual components in a complex are processed independently in the auditory system, except for partial masking. In other words, it is assumed that the transformation into specific loudness reflects the intensity of each component separately. Whereas the frequency separation of at least 1 Bark ensures that this assumption is likely to be fulfilled for normal listeners, reduced frequency selectivity in cochlear hearing losses (e.g., Scharf and Hellman 1966; Scharf 1978a; Florentine et al. 1980; Scharf and Florentine 1982; Moore 1998) could cause it to be violated. However, reduced frequency selectivity is most apparent in experiments, such as psychoacoustical tuning curves, masking patterns, and auditory-filter shapes, that involve off-frequency masking. It is unclear whether the critical bandwidth, defined as the bandwidth over which component frequencies are processed together, is widened. In fact, Scharf (1978a) concluded that listeners with cochlear hearing losses show no clear increase in critical bandwidths determined by masked thresholds in wideband noise, whereas other masking measurements clearly reveal that frequency selectivity is reduced. Likewise, Pick et al. (1977) found that the slopes and stop-band rejection of auditory filters measured by masking with comb-filtered noise decreased gradually with increasing hearing loss, whereas the bandwidth of the central part of the filter was relatively unaffected by hearing loss, except for large hearing losses. This indicates that the independence of the components separated by more than 1 
Bark is likely to hold also for listeners with cochlear hearing losses and that reduced frequency selectivity is likely to manifest itself primarily as larger-than-normal mutual masking among the components.

Several aspects of the present data support the independence of the components in the tone complexes used in the present study. One line of evidence comes from the detection thresholds for the tone complexes. If multiple components were processed within a single auditory channel, one would expect their intensities to add. (This follows because their pressure waveforms add and because sinusoids at different frequencies generally are uncorrelated. Accordingly, the overall intensity of a sum of sinusoids is equal to the sum of the intensities of the individual sinusoids.) If all components were to fall into one abnormally wide auditory channel, the expected thresholds are $-6 \mathrm{~dB}$ SL per component for four-tone complexes and -10 $\mathrm{dB}$ SL for ten-tone complexes. In contrast, if the components are processed independently, a multichannel energy-detector model predicts that the thresholds should be $-3 \mathrm{~dB}$ SL per component for four-tone complexes and $-5 \mathrm{~dB}$ SL for ten-tone complexes (e.g., Buus et al. 1986). For three of the five listeners, the thresholds for the tone complexes closely follow expectations for independently processed components. For L1, L2, and L3, the thresholds showed no systematic effects of frequency separation and averaged between -2.7 (L2) and -3.4 dB SL (L1) for four-tone complexes and between -3.7 (L2) and $-7.9 \mathrm{~dB}$ SL (L1) for ten-tone complexes. These values are within the range obtained for normal listeners by Buus et al. (1998), and the averages across the three listeners, $-3.0 \mathrm{~dB}$ SL for four-tone complexes and $-5.8 \mathrm{~dB} \mathrm{SL}$ for ten-tone complexes, are close to the values expected for independently processed components.

The thresholds for L4 and L5 differ from those predicted by a multichannel energy-detector model. For L4, the thresholds appeared to increase systematically with frequency separation, which might be taken to indicate a change from the components being processed together at narrow frequency separations to independent processing at wide frequency separations. However, for the 1-Bark frequency separation, L4's threshold for the four-tone complex was $-8.8 \mathrm{~dB}$ SL per component ( $\pm 0.7 \mathrm{~dB} \mathrm{SE})$, which is well below the threshold of $-6 \mathrm{~dB}$ SL expected if the components were processed together in a single, abnormally wide auditory channel. This indicates that L4's unusual thresholds cannot be ascribed to a failure of the independence assumption. The thresholds obtained for the tone complexes in L5 also differ from normal, but they do not appear compatible with reduced frequency selectivity. The thresholds for four-tone complexes show no systematic effect of frequency separation and the average of $-8.0 \mathrm{~dB}( \pm 0.8 \mathrm{~dB} \mathrm{SE})$ is lower than the $-6 \mathrm{~dB}$ expected if all four components were processed in a single, abnormally wide channel. The thresholds for the ten-tone complexes are close to $-10 \mathrm{~dB}$ SL per component. Although this value is consistent with all components being processed in a single auditory channel, it seems unlikely that frequency selectivity would be reduced so much that a single auditory channel encompasses all components of the ten-tone complexes. [One might think that L5 may have extensive "dead" regions (cf. Florentine and Houtsma 1983; Moore et al. 2000) and that this would explain his anomalous thresholds for tone complexes. However, "dead" regions seem unlikely to explain the data. If some component frequencies were within "dead" regions, one might expect that they would be processed together with components outside the "dead" regions, in which case the thresholds for the complexes ought to follow expectations for listeners with abnormally wide auditory channels. As stated above, the data for L5 are not compatible with this expectation. Another possibility is that components within a "dead" region would not contribute to detection of the complex. If so, one would expect the thresholds for the complexes (in terms of $\mathrm{dB}$ SL per component) to be abnormally high, which also is not compatible with the data.] Altogether, it is clear that the thresholds for the tone complexes are not consistent with multiple components being processed together in abnormally wide auditory channels.

Additional evidence for the independence of the individual components of the tone complexes comes from the loudness matches. If reduced frequency selectivity caused the independence assumption to be violated, one would expect the data to show systematic variations as the frequency separation between components increased. As pointed out in the Results section, the results for $\mathrm{L} 1$, who has a relatively flat hearing loss over most of frequency range used in the present experiment, did not indicate any systematic effect of frequency separation on the loudness matches at low SLs. The same is true for L2 for the four-tone complexes with frequency separations of 1, 2, and 4 Barks. As noted earlier, she judged the tone complexes with the widest frequency separations softer than the other tone complexes, as would be expected if the loudness at threshold depends on the hearing loss. The data for the third listener with a more or less flat hearing loss, L5, also do not show any consistent differences between low-SL four-tone complexes with frequency separations of 1, 2, and 4 Barks. The four-tone complex with the 6-Bark frequency separation was judged somewhat louder than the other four-tone complexes, which is contrary to what one would expect if the local exponent of his loudness function were abnormally large and only widely separated components were processed independently. The data for the two remaining 
listeners are difficult to evaluate. These listeners' hearing losses change markedly across frequency, which makes it difficult to distinguish effects of frequency separation, per se, from effects caused by the variation of loudness at threshold with frequency. Overall, it is clear that the loudness-matching data are reasonably consistent with independent processing of the components, regardless of the frequency separation.

The conclusion that the present data appear consistent with independent processing of the individual components, even for the 1-Bark component separation, is contrary to Scharf and Hellman's (1966) conclusion that widened critical bands were the most likely explanation for small but consistent differences between their data for listeners with cochlear hearing losses and predictions by Zwicker's (1958; Zwicker and Scharf 1965; Zwicker and Feldtkeller 1967) model of loudness summation when the hearing loss was modeled as partial masking. Although the discrepancies were small, Scharf and Hellman believed that they might be meaningful because model predictions of loudness-level gain owing to loudness summation agreed with data obtained under partial masking. (The loudness-level gain owing to loudness summation is defined as the difference in overall level between a tone and an equally loud tone complex. Many authors refer to this quantity as "loudness summation.") However, this finding does not necessarily indicate abnormally wide critical bandwidths for the listeners with hearing losses. As discussed below, it is consistent with subtle differences between the loudness functions obtained in listeners with cochlear hearing losses and in masked normal listeners.

The model predicts a small loudness-level loss owing to loudness summation near threshold because it assumes that the loudness increases more rapidly than intensity (i.e., the local exponent is larger than unity) near a threshold that is elevated by masking. If the local exponent is unity, no loudness-level gain (or loss) owing to loudness summation should be obtained, and if the local exponent is less than unity, the loudnesslevel gain owing to loudness summation should be positive. The present data, as well as Hellman's data (e.g., Hellman and Meiselman 1990, 1993; Hellman 1999), indicate that the local exponents of the loudness functions at low SLs are near unity and are similar for normal listeners and listeners with cochlear hearing losses. On the other hand, Buus (2000) found that the local exponent of loudness functions at low SLs were about $30 \%$ larger under partial masking than in the quiet for three normal listeners tested in both conditions. Thus, one might expect that the loudnesslevel gain owing to loudness summation at low SLs should be the same in normal listeners and listeners with cochlear hearing losses, but could be slightly negative in listeners with partial masking.
The latter expectation is borne out by Scharf and Hellman's (1966) data, which show that the loudnesslevel gain owing to loudness summation at $5 \mathrm{~dB}$ SL is the same for listeners with cochlear hearing losses and listeners with conductive losses. In contrast, normal listeners with partial masking showed about a 2-dB loudness-level loss owing to loudness summation. At $10 \mathrm{~dB}$ SL, the data for listeners with cochlear hearing losses fell between those for listeners with conductive losses and normal listeners with broadband masking. At 20 and $30 \mathrm{~dB}$ SL, little difference was apparent between the listeners with cochlear hearing losses and normal listeners with broadband masking. For both groups, the loudness-level gain owing to loudness summation was small as would be expected at high SPLs. (The only difference apparent between the two groups is that the loudness-level gain owing to loudness summation for the 2200-Hz-wide complex at $30 \mathrm{~dB} \mathrm{SL}$ is about $2.5 \mathrm{~dB}$ larger in the masked normal listeners than in the listeners with hearing losses, but as noted by Scharf and Hellman, this could result from greaterthan-normal spread of excitation in the listeners with cochlear hearing losses.) Altogether, Scharf and Hellman's (1966) data do not necessarily indicate widened critical bands in listeners with cochlear hearing losses. Their data are compatible with normal local exponents of their loudness functions near threshold, and the small difference between listeners with cochlear hearing losses and normal listeners with broadband masking seems likely to reflect that the local exponent of the loudness function near threshold is subtly increased by broadband masking but not by hearing loss.

These considerations-together with the evidence culled from the present data-indicate that widened critical bands are unlikely to affect the estimation of loudness functions on the basis of loudness summation. The primary effect of reduced frequency selectivity appears to be an increase in off-frequency masking, which may well increase mutual masking among the components of tone complexes, but this effect is readily accounted for by the model used to derive loudness functions from the loudness matches.

\section{Comparison between normal listeners and listeners with hearing losses}

As shown in Table 2, the low-level asymptotic exponents of the loudness functions for the listeners with hearing losses are within the range of 1.04-2.31 obtained for normal listeners by Buus et al. (1998). In addition, the average low-level asymptotic exponent for the listeners with hearing losses is identical to the normal average of 1.43. Likewise, $S N R_{\mathrm{th}} \mathrm{s}$ (the threshold signal-to-noise ratios within a critical band centered on the tone) for the best-fitting pure-tone loudness functions are generally within the range of 
-11.9 to $-1.8 \mathrm{~dB}$ obtained for normal listeners, and the mean of $-4.6 \mathrm{~dB}$ is not far from the normal mean of $-7.6 \mathrm{~dB}$ and is close to the value of $-4 \mathrm{~dB}$ assumed by Zwislocki (1965) for normal listeners. Thus, the present data show that the form of the low-level part of the pure-tone loudness function is the same for normal listeners and listeners with cochlear hearing losses. As shown in Table 2, the local exponents of the loudness functions evaluated at 0 and $10 \mathrm{~dB} \mathrm{SL}$ reinforce this conclusion. At $0 \mathrm{~dB} \mathrm{SL}$, they ranged from 0.94 to 1.78 for the present listeners with hearing losses; the range was 0.96-2.04 for the normal listeners tested by Buus et al. (1998). The average local exponents were almost identical: 1.26 for the listeners with hearing losses in the present experiment and 1.31 for the normal listeners in our previous experiment. At $10 \mathrm{~dB} \mathrm{SL}$, the local exponents ranged from 0.55 to 0.96 for the listeners with hearing losses and from 0.60 to 1.20 for the normal listeners; the average local exponents were 0.74 for the listeners with hearing losses and 0.87 for the normal listeners. Thus, the present data show that rate of loudness growth near threshold is the same for normal listeners and listeners with cochlear hearing losses.

Whereas the parameters for the low-level part of the loudness function are clearly similar for normal listeners and listeners with hearing losses, differences are apparent at higher SLs. As noted in the Results section, the high-level asymptotic exponents $s_{\text {hi }}$, tended to be steeper for the listeners with hearing losses (average: 0.28; range: 0.12-0.48) than for the normal listeners in our previous study (average: 0.087 ; range: $0.0001-0.16$ ). This was especially true for $\mathrm{L} 4$ and L5, but L1 and L2 also yielded $s_{\mathrm{hi}} \mathrm{s}$ that exceed the range of values obtained for normal listeners. The exception is L3, whose thresholds were nearly normal at and below $1600 \mathrm{~Hz}$. This indicates that the loudness functions for listeners with elevated thresholds may have local exponents that are somewhat larger than normal at moderate SLs. As shown in Table 2, the local exponents for L1, L4, and L5, whose hearing losses are substantial, are larger than normal at $20 \mathrm{~dB}$ SL (normal range: 0.33-0.50). As discussed below, there are at least three factors that may account for this finding.

The first factor relates to the somewhat limited range of levels encompassed by the stimuli used for the listeners with hearing losses. The listeners with elevated thresholds were tested only at levels up to about $25 \mathrm{~dB}$ SL, whereas the listeners with normal hearing were tested at levels up to about $50 \mathrm{~dB}$ SL. Thus, the estimates of $s_{\text {hi }}$ pertain to lower SLs in the listeners with hearing losses than in normal listeners. Because the local exponent of the normal loudness function is larger at 25 than at $50 \mathrm{~dB}$ SL, the model is likely to provide an enlarged estimate of $s_{\text {hi }}$ when data for levels above $25 \mathrm{~dB}$ SL are lacking. Indeed, if tone levels above $25 \mathrm{~dB}$ SL are eliminated from the data for normal listeners in the study by Buus et al. (1998), the model fits yielded an average value of $s_{\mathrm{hi}}$ equal to 0.25 , compared with that of 0.087 obtained when the entire data set is used. This finding indicates that the limited range of levels used for the listeners with hearing losses is likely to result in enlarged estimates of $s_{\text {hi }}$, simply because data above 25 SL are necessary to obtain a good estimate of the local exponent at moderate sensation levels, at least for normal listeners.

The second factor relates to the reduced outer-haircell function that is likely to be present in most of our listeners. In normal listeners, the loudness function is highly compressive at moderate levels; the local exponent is about 0.2 around $40 \mathrm{~dB}$ SL (Buus et al. 1998), which is thought to reflect that normal outer hair cells reduce the basilar-membrane gain rapidly as the sound level increases (e.g., Yates 1990; Ruggero et al. 1997; de Boer and Nuttall 2000). If outer-hair-cell function is reduced, one would expect the compression at moderate levels to diminish, which ought to enlarge the local exponent for the moderate-SL part of the loudness function in listeners with cochlear hearing losses. In other words, it is quite possible that the enlarged $s_{\mathrm{hi}} \mathrm{s}$ obtained for the listeners with hearing losses reflect that the midlevel compression is less than normal in cochlear hearing losses. It is noteworthy that the Hellman and Meiselman (1990) data appear to indicate reduced compression over a limited range of SLs somewhat above threshold for their listeners with cochlear hearing losses, although the authors did not discuss this effect.

The third factor relates to the fact that moderate SLs correspond to higher SPLs in listeners with hearing losses than in normal listeners. Recent studies indicate that the local exponent of the normal loudness function is larger at high than at moderate SPLs (Florentine et al. 1996, 1998; Buus et al. 1997, 1999). It is smallest between 40 and $50 \mathrm{~dB}$ SPL and appears to increase above $70 \mathrm{~dB}$ SPL or so. If perception of loudness by listeners with cochlear hearing losses is approximately normal at SPLs well above their elevated thresholds, their loudness function ought to be steeper than normal at moderate SLs because the corresponding SPLs are higher than normal. This explanation is supported by loudness functions obtained in masked normal listeners. Buus (2000) observed that the local exponents of normal listeners' loudness functions at 20 and $40 \mathrm{~dB}$ SL were larger under masking than in the quiet.

The increase of the local exponent at high SPLs appears consistent with basilar-membrane mechanics, even if it seems contrary to observations of nearly undiminished compression in the basilar-membrane input-output function for levels up to at least $100 \mathrm{~dB}$ 
SPL (e.g., Ruggero et al. 1997). In large part, the compression observed at high SPLs results because the place of measurement is fixed, whereas the place of maximal vibration to a fixed-frequency tone migrates toward the base at high sound levels (Summers and Leek 1998). This means that the vibration amplitude measured in response to a tone that yields maximal vibration amplitude at the place of measurement for low SPLs (i.e., a best-frequency tone) will be less than maximal at high SPLs. This can readily be seen in Figure 7 of the article by Ruggero et al. (1997). As the sound level increases above $60 \mathrm{~dB}$ SPL, the largest response is produced by frequencies below $10 \mathrm{kHz}$, which is the best frequency. Presumably, the $10-\mathrm{kHz}$ tone produces a similarly large response at a place somewhat basal to the place of measurement. Thus, the apparent compression of best-frequency tones at high SPLs results because the fixed-place measurement reflects the diminished vibration on the apical cutoff of the traveling wave when the SPL exceeds 60 dB SPL.

Because loudness almost certainly reflects an integration of the activity in fibers distributed across the entire basilar membrane, the place at which the vibration occurs is likely to be relatively unimportant for the loudness produced by some stimulus. The important factor is the amount of activity, wherever it occurs. Therefore, a first approximation to the relation between loudness and basilar-membrane vibration reasonably can be thought to reflect the maximal vibration amplitude that a given tone produces anywhere along the basilar membrane. Owing to the trading of frequency and place, one may also consider the maximal vibration amplitude produced by any frequency at some fixed place (assuming that the transfer function between the sound source and the inner ear is relatively independent of frequency; see also de Boer and Nuttall 2000). Viewed in this manner, the data in Figure 7 of Ruggero et al. (1997) indicate that the normal loudness function ought to be considerably less compressive at high than at moderate SPLs. Accordingly, one would expect the local exponent at moderate SLs to be larger for listeners with hearing loss (for whom the SPL is relatively high) than for normal listeners (for whom the SPL is moderate), if the local exponent of the loudness functions for listeners with hearing losses is approximately normal at SPLs well above their elevated thresholds.

Implications for loudness growth in listeners with hearing losses: Recruitment reconsidered

The most important finding of the present study is that the local exponent of the loudness function near threshold is the same for normal listeners and listeners with hearing losses. This finding is in stark contrast to the long-held notion of recruitment as an abnormally rapid growth (i.e., an abnormally large local exponent) near the elevated thresholds of listeners with cochlear hearing losses (e.g., Fowler 1937; for review, see Brunt 1994; Moore 1998). However, it agrees with conjectures by Hellman and co-workers (e.g., Hellman and Zwislocki 1964; Hellman and Meiselman 1990; Hellman 1999). Like Steinberg and Gardner (1937), Hellman and Zwislocki (1964) noted that loudness matches between tones in quiet and tones partially masked by a 1-octave-wide noise were very similar to loudness matches between tones at frequencies with normal hearing and tones at frequencies with cochlear hearing loss. Based on extrapolation of loudness data obtained for normal listeners tested at levels down to $4 \mathrm{~dB}$ SL in a 1-octave-wide masking noise, Hellman and Zwislocki (1964) suggested that the local exponent of loudness functions near threshold should approach unity for listeners with hearing losses as well as for normal listeners in quiet and under broadband masking. It may seem paradoxical that Hellman and Meiselman (1990) concluded that "for hearing losses greater than $40 \mathrm{~dB}$, the values of the individual and mean slopes [i.e., local exponents] . . . are clearly larger than those obtained in normal hearing. The larger slope values are indicative of cochlear involvement" (p. 2604). They stated that " most of the slopes for normal hearing lie between 0.20 , and 0.35 , with a mean close to the standard value of 0.30 , while for cochlear-impaired hearing they lie between 0.52 and 1.46 , with a mean close to 1.0" (p. 2600. Note that the slope values quoted here are half those [ $r e$ sound pressure] stated by Hellman and Meiselman. This change makes them comparable to the local exponents [ $r$ sound intensity] used in the present article). However, the difference between normal listeners and listeners with hearing losses resulted because the local exponents were estimated for levels just above $4 \mathrm{~dB}$ SL for the listeners with hearing losses, but at levels "over which a simple power function obtains" (Hellman and Meiselman 1988) i.e., above $30 \mathrm{~dB}$ SL or so for normal listeners. The local exponents obtained by Hellman and Meiselman (1990) are consistent with Hellman and Zwislocki's (1964) hypothesis and agree closely with the local exponents obtained at $5 \mathrm{~dB}$ SL for the listeners in the present study (range: 0.77-1.14; average: 0.99). In summary, it is clear that local exponents near threshold are no larger in listeners with hearing losses than in listeners with normal hearing. Contrary to the assertions by Hellman and coworkers, however, it appears that asymptotic low-level exponent $s_{\mathrm{lo}}$ is somewhat larger than unity in both listeners with hearing loss as indicated by the present study and normal listeners as indicated by our previous study (Buus et al. 1998).

The classical notion of recruitment often is stated 
to be consistent with decreased compression due to outer-hair-cell damage (Patuzzi 1993; Moore and Glasberg 1997; Moore 1998). However, the rate of loudness growth near threshold is likely to be relatively independent of outer-hair-cell function, because the basilar-membrane gain is nearly constant within 10 or 15 dB (Yates 1990; Ruggero et al. 1997) or even $30 \mathrm{~dB}$ (de Boer and Nuttall 2000) of threshold. In other words, the basilar-membrane response grows linearly near threshold whether the threshold is normal or is elevated because of cochlear hearing losses. Accordingly, one might expect the rate of loudness growth near threshold to be the same in normal listeners and in listeners with hearing losses, assuming that loudness bears a relatively simple relationship to the vibration amplitude of the basilar membrane (Buus et al. 1997; Schlauch et al. 1998). In summary, the present finding that loudness grows at similar rates near threshold in normal listeners and listeners with hearing losses is consistent with expectations derived from careful consideration of basilar-membrane mechanics, as well as with data obtained with magnitude matching and cross-modality matching.

The finding that loudness grows at a normal rate for the first 10-15 dB above the elevated threshold of a listener with hearing loss requires a new explanation for the fact that loudness often is nearly normal at high SPLs. The present data indicate that the likely explanation is that loudness at threshold is larger than normal when threshold is elevated by a cochlear hearing loss, although somewhat enlarged local exponents over a narrow range of levels around $20 \mathrm{~dB}$ SL also contribute to the "catching up" of loudness. The finding that loudness at threshold is enlarged when the threshold intensity is elevated agrees with conjectures that may be derived from the extension of Zwislocki's (1965) model used by Hellman and Meiselman (1990) to fit their loudness estimates for listeners with hearing losses. They assumed that a hearing loss could be described by increasing the bandwidth and level of the internal noise that accounts for absolute threshold. This leads to an increase in the loudness at threshold when the threshold is elevated. Using the parameters found to describe the data above $6 \mathrm{~dB}$ SL, Hellman and Meiselman's (1990) model yields a loudness at threshold for a listener with a 65- $\mathrm{dB}$ hearing loss that is 5.5 times larger than the calculated loudness at threshold for a normal listener, but the increase in loudness at threshold depends strongly on the assumed increase in the bandwidth of the internal noise.

In the present study, the model used to derive the pure-tone loudness functions indicates that, on the average, the loudness at threshold doubles for every 16 $\mathrm{dB}$ of hearing loss. Whereas this average value appears reasonable, as discussed below, it should be noted that the extent to which loudness at threshold is elevated by a given hearing loss is apt to vary across individuals depending on the pathology underlying the hearing loss. It is likely to depend on the balance between inner- and outer-hair-cell dysfunction. In addition, it may depend on specific aspects of the inner-hair-cell dysfunction, such as whether it is primarily a loss of responsiveness for the most sensitive fibers or is an attenuation of the response throughout the dynamic range for all auditory nerve fibers. Certainly, the values of $s_{\mathrm{HL}}$ obtained from the model fits in the present study showed substantial differences across listeners. They ranged from 0.14 to 0.62 for the three listeners with hearing losses that varied considerably across the range of component frequencies, which indicates that loudness at threshold increases systematically with the amount of hearing loss within each listener, but the rate of increase differs across listeners.

Two other listeners (L1 and L5) have audiograms that are relatively flat over the range of frequencies encompassed by the present stimuli. The small range of hearing losses makes it difficult to estimate how the amount of hearing loss affects loudness at threshold by the within-listener comparisons employed by the model. Therefore, the lack of a positive relation between the amount of hearing loss and the loudness at threshold for L1 and L5 should not be taken to indicate that loudness at threshold is normal for these listeners. Inspection of Figure 3 indicates that the loudness functions calculated for L1 and L5 on the basis of the average value of $s_{\mathrm{HL}}$, if anything, underestimate how much loudness at threshold is increased for these listeners. Although loudness at the elevated thresholds for L1 and L5 is about 20 times the normal loudness at threshold, their loudness functions fail to reach normal loudness for high-SPL tones. Given the severity of these listeners' hearing losses, some reduction of the loudness, even at high SPLs, is quite plausible, but reasonable loudness functions for L1 and L5 cannot be positioned much lower than those shown. Thus, it appears that Hellman and Meiselman (1990) model may underestimate the extent to which loudness at threshold is elevated by a hearing loss, at least with the parameters they used to fit their data. In any event, if the loudness functions for L1 and L5 were positioned to make loudness at threshold equal to that for normal listeners, the predicted loudness for high-SPL tones would be unreasonably small. This is also true for the other listeners with elevated thresholds. Thus, it appears to be an inescapable conclusion that loudness at threshold is larger than normal when the threshold is elevated by cochlear pathology. Altogether, the present data indicate that recruitment should be redefined as an abnormally large loudness at an elevated threshold, which is an important change from the classical definition of recruitment as an abnormally rapid growth of loudness 


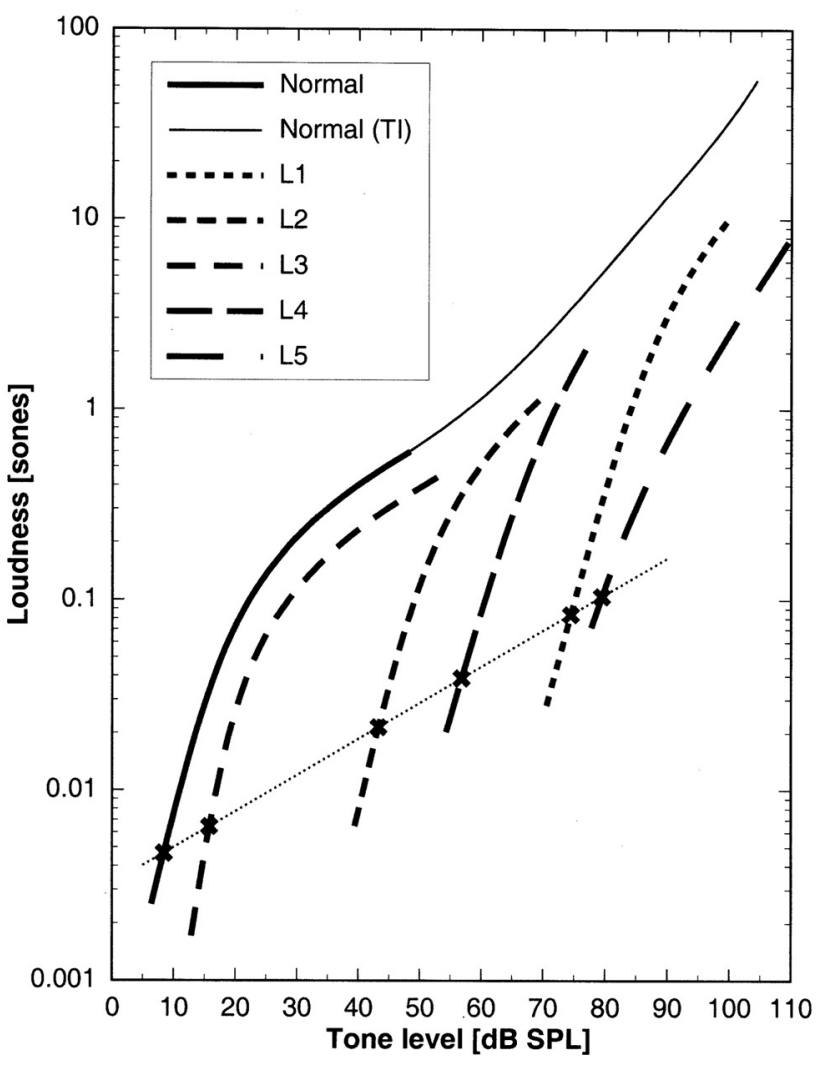

FIG. 3. Loudness functions for normal listeners (solid lines) and five listeners with cochlear hearing losses (dashed lines). The loudness in sones is plotted as functions of the tone's SPL. The loudness functions for the listeners with hearing losses are derived from the data in Figure 2 and are limited to the range of levels encompassed by the loudness matches. [The highest level is less than the stimulus range for L3, because Eqs. (4) and (5) are appropriate descriptions of the loudness function only for levels below about $40 \mathrm{~dB}$ SL.] The normal listeners' loudness function is obtained by combining loudness functions obtained in two different experiments. Below 43 $\mathrm{dB}$ SPL (thick solid line), it is derived by the method used in the present experiment (Buus et al. 1998). Above $23 \mathrm{~dB}$ SPL, the normal loudness function is derived from temporal-integration data (Florentine et al. 1998). Because the loudness functions obtained with the present method and from temporal integration agree between 23 and $43 \mathrm{~dB} \mathrm{SPL}$, the exact level at which transition is made from one to the other is unimportant. The $X^{\prime}$ 's mark the threshold and loudness at threshold for each listener or group. As indicated by the dotted line, which is a power function of intensity with an exponent of 0.19 , the loudness functions for the listeners with hearing losses have been scaled to elevate the loudness at their elevated threshold according to the average loudness elevation obtained from the simple model of loudness summation discussed in the text.

above an elevated threshold. Of course, it is possible that some types of pathology may alter the loudness function to yield an abnormally large local exponent near threshold, but this certainly did not occur among the five listeners tested in the present study and other data (Hellman and Meiselman 1990) indicate that it would be extremely rare, if it occurs at all.

As noted in the Introduction, this redefinition of recruitment is consistent with the steeper-than-normal functions obtained for loudness matches between tones for which thresholds are normal and tones for which thresholds are elevated by cochlear hearing losses (e.g., Steinberg and Gardner 1937; MiskolczyFodor 1960). If loudness at threshold is increased when the threshold is elevated by cochlear pathology, tones near an elevated threshold in a listener with hearing loss may be as loud as a moderate-SL tone at frequencies with normal thresholds. Because the normal loudness function is highly compressive at moderate SLs, the level of a tone with normal threshold must be raised much more than the level of a tone in the region of elevated thresholds to maintain equal loudness. According to this view, the steep loudnessmatching function between tones in regions with normal thresholds and tones in regions with elevated thresholds does not result because the loudness function is less compressive near threshold for listeners with hearing losses than for normal listeners. As illustrated in Figure 1, the steep loudness-matching function results because increased loudness at an elevated threshold (together with a normal, somewhat fasterthan-linear growth of loudness near threshold) makes the loudness of a low-SL tone in an ear with hearing loss equal to the loudness of tones in the highly compressive moderate-SL portion of the normal loudness function. In addition, somewhat enlarged local exponents around $20 \mathrm{~dB}$ SL also contribute to the steep slope of the loudness-matching functions between tones in regions of normal hearing and tones in regions of hearing loss.

Figure 4 illustrates that the loudness functions obtained in the present study are entirely consistent with the classic studies on loudness matching. It shows predicted loudness matches between a tone for which threshold is elevated by hearing loss and a tone for which the threshold is normal. The matching functions were derived by finding the loudness corresponding to a given SPL for the listener with hearing loss according to the loudness function in Figure 3 and then finding the SPL needed to obtain the same loudness according to the normal loudness function in Figure 3. The low-SL slopes of the matching functions generally increase as the hearing loss increases, similar to the general tendency observed by Miskolczy-Fodor (1960). L5 deviates somewhat from this general tendency, but the deviation is well within the range of loudness-matching functions indicated by MiskolczyFodor's (1960) data. It also is noteworthy that the derived matching functions in Figure 4 tend to have sigmoidal shapes and be less steep in the immediate vicinity of the elevated threshold than at somewhat higher SLs. This form of the loudness-matching functions agrees with Hellman and Zwislocki's (1964) summary of Miskolczy-Fodor's data and with loudnessmatching functions obtained with several procedures 


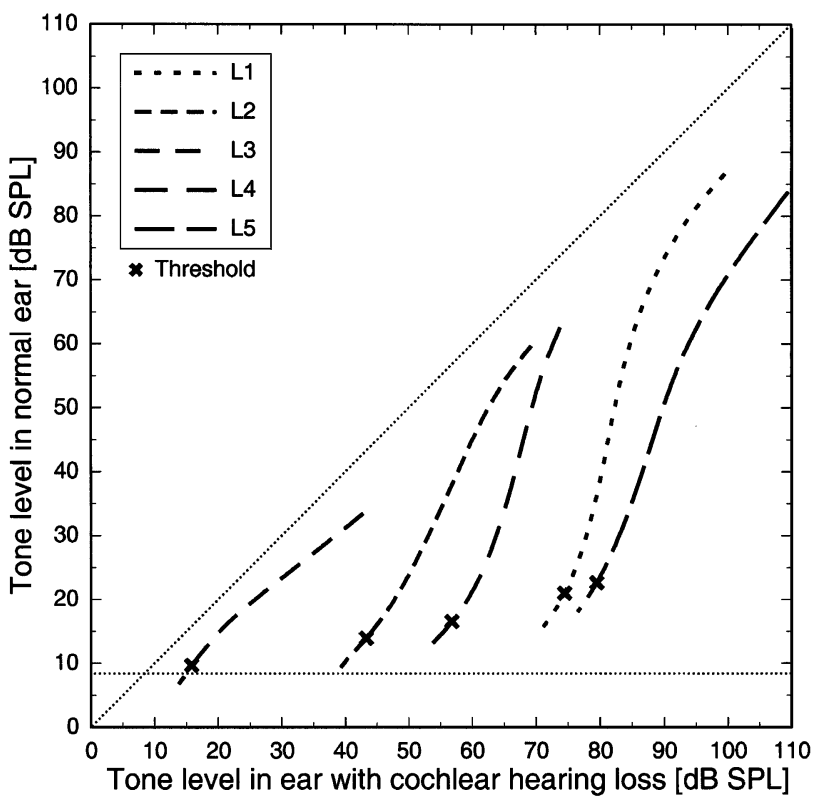

FIG. 4. Predicted loudness matches between a tone for which the threshold is elevated by hearing loss and a tone for which the threshold is normal. The matching functions are derived as pairs of SPLs yielding the same loudness for a listener with hearing loss and an average normal listener according to the loudness functions in Figure 3. The $x^{\prime}$ 's show threshold for the listeners with hearing losses. The horizontal dotted line indicates the threshold for normal listeners (8.4 dB SPL). The diagonal indicates equal SPL in the normal ear and the ear with hearing loss.

for individual listeners, as shown by Hellman (1997). The tendency of the derived matching function for L3 to have a slope less than unity is consistent with his abrupt hearing loss, which causes a reduction of loudness and a reduced rate of loudness growth at levels well above threshold (cf., Florentine et al. 1997). Altogether, it is clear that the loudness functions obtained in the present study are consistent with a wide variety of data on loudness in listeners with hearing losses, although they contradict the classic notion of recruitment as an abnormally large local exponent of the loudness function near a threshold that is elevated by cochlear hearing loss.

Whereas the finding of a normal rate of loudness growth near elevated thresholds in listeners with hearing losses appears to be consistent with the linearity of basilar-membrane input-output function near threshold for both normal listeners and listeners with hearing losses, the explanation of the greater-thannormal loudness at a threshold that is elevated by hearing loss remains speculative. Although part of the threshold elevation is likely to reflect the reduced basilar-membrane gain that results from damage to the outer hair cells in most cases of cochlear hearing loss, additional threshold elevations may be caused by increased internal noise. If the internal noise were increased, an enlarged excitation would be needed to make a stimulus audible, which in turn would cause the average loudness at threshold to increase (cf. Hellman 1994). Another possibility is that part of the threshold elevation results because the most sensitive low-threshold fibers may be more vulnerable to damage than higher-threshold fibers. If low-threshold fibers fail to respond in ears with hearing losses, detection would be mediated by fibers that respond to suprathreshold sounds in normal listeners. Following the idea that excitation in a single frequency-selective auditory channel is coded by a combination of fibers working together to encompass the entire dynamic range (e.g., Delgutte 1987; Viemeister 1988), threshold responses by such higher-threshold fibers ought to correspond to a greater loudness than threshold responses of lowthreshold fibers. Accordingly, the loudness at threshold will be elevated in listeners with hearing losses if part of their hearing loss results because low-threshold fibers fail to respond. At present, we are unaware of data that might support or refute one or the other hypothesis, but it seems possible that one or perhaps both of these mechanisms might account for the finding that loudness at threshold appears to be larger in listeners with hearing losses than in normal listeners.

\section{CONCLUSIONS}

The present study used loudness matches between tones and tone complexes to assess the rate of loudness growth near the elevated thresholds of listeners with hearing losses of primarily cochlear origin. A simple model of loudness summation provided good fits to the data and provided highly consistent estimates of the form of the listeners' loudness functions at low sensation levels (SLs). The results show the following:

1. The local exponent of the loudness function near threshold is the same for normal listeners and listeners with cochlear hearing losses.

2. A normal local exponent of the loudness function near a threshold that is elevated by cochlear pathology is consistent with basilar-membrane mechanics, because the basilar-membrane input-output function is nearly linear within the first 10 or $15 \mathrm{~dB}$ of threshold whether the threshold is normal or is elevated by a cochlear hearing loss.

3. Loudness at threshold is greater than zero and increases with the amount of hearing loss. The simple model of loudness summation indicates that, on average, the loudness at threshold doubles for each $16 \mathrm{~dB}$ of hearing loss. For any particular listener, the loudness at threshold may well deviate from this average because it is highly likely to depend on the pathology underlying the hearing loss. 
4. The present findings of loudness functions that have normal local exponents near threshold and have increased loudness at elevated thresholds are consistent with classical data on loudness matches between tones for which thresholds are normal and tones for which thresholds are elevated by cochlear hearing losses.

5. At moderate SLs, the local exponent of the loudness function tends to be larger for listeners with hearing losses than for normal listeners tested at the same SL. This finding may, at least in part, reflect reduced outer-hair-cell function. In addition, it may reflect that the local exponent of the normal loudness function increases at high SPLs. As the SPL becomes high and the SL exceeds 15-30 dB SL, the local exponents of the loudness functions for listeners with hearing losses appear to approach those for normal listeners tested at the same SPLs.

6. These findings indicate that it is likely to be more appropriate to define recruitment as an abnormally large loudness at an elevated threshold instead of as an abnormally rapid growth of loudness above an elevated threshold. As pointed out in Conclusion 5 , however, the local exponent of the loudness function tends to be enlarged at moderate SLs for listeners with hearing losses.

\section{ACKNOWLEDGMENTS}

The authors thank Robert Shannon and Peter Marvit for helpful comments on an earlier version of this article and Van Summers for pointing out the implications of the basalward shift in excitation patterns for measurements of basilarmembrane compression at high SPLs. We are also grateful to Brian Moore, Jont Allen, and Rhona Hellman for their insightful reviews. Hannes Müsch and Mary Beth O'Sullivan helped with data collection. This research was supported by NIH/NIDCD grant number R01DC02241.

\section{REFERENCES}

ALlen JB. Harvey Fletcher's role in the creation of communication acoustics. J. Acoust. Soc. Am. 99:1825-1841, 1996.

ALLEN JB. Derecruitment by multiband compression in hearing aids. In: Jesteadt W, (ed) Modeling Sensorineural Hearing Loss. Erlbaum Mahwah, NJ, 1997, p. 99-112.

ANSI (1989) S3.6-1989 Specifications for audiometers. American National Standards Institute, New York.

BRUNT MA. Tests of cochlear function. In: Katz J, (ed) Handbook of Clinical Audiology, 4th ed. Williams and Wilkins Baltimore, MD, 1994, p. 165-175.

BuUs S. On the growth of loudness near thresholds elevated by masking. In: Schick A, Meis M, Reckhardt C, (eds) Contributions to Psychological Acoustics. Oldenburg University Oldenburg, Germany, 2000, p. 65-84.
Buus S, Florentine M, Poulsen T. Temporal integration of loudness, loudness discrimination, and the form of the loudness function. J. Acoust. Soc. Am. 101:669-680, 1997.

Buus S, Florentine M, Poulsen T. Temporal integration of loudness in listeners with hearing losses of primarily cochlear origin. J. Acoust. Soc. Am. 105:3464-3480, 1999.

BuUs S, MÜsch H, Florentine M. On loudness at threshold. J. Acoust. Soc. Am. 104:399-410, 1998

Buus S, Schorer E, Florentine M, Zwicker E. Decision rules in detection of simple and complex tones. J. Acoust. Soc. Am. 80:1646-1657, 1986.

dE Boer E, Nuttall AL. The mechanical waveform of the basilar membrane. III. Intensity effects. J. Acoust. Soc. Am. 107:14971507, 2000.

DELGUTTE B. Peripheral auditory processing of speech information: Implications from a physiological study of intensity discrimination. In: Schouten MEH, (ed) The Psychophysics of Speech Perception. Nijhoff Dordrecht, The Netherlands, 1987.

Fletcher H, Munson WA. Loudness, its definition, measurement and calculation. J. Acoust. Soc. Am. 5:82-108, 1933.

FLeTCHER H, Munson WA. Relation between loudness and masking. J. Acoust. Soc. Am. 9:1-10, 1937.

Fletcher H, Steinberg JC. The dependence of the loudness of a complex sound upon the energy in the various frequency regions of the sound. Phys. Rev. 24:306-317, 1924.

Florentine M, BuUs S, Hellman RP. A model of loudness summation applied to high-frequency hearing loss. In: Jesteadt W, (ed) Modeling Sensorineural Hearing Loss. Erlbaum Mahwah, NJ, 1997, p. 187-198.

Florentine M, BuUs S, Poulsen T. Temporal integration of loudness as a function of level. J. Acoust. Soc. Am. 99:1633-1644, 1996.

Florentine M, BuUs S, Robinson M. Temporal integration of loudness under partial masking. J. Acoust. Soc. Am. 104:999-1007, 1998.

Florentine M, Buus S, Scharf B, Zwicker E. Frequency selectivity in normally-hearing and hearing-impaired observers. J. Speech Hear. Res. 23:643-669, 1980.

Florentine M, Houtsma AJM. Tuning curves and pitch matches in a listener with a unilateral, low-frequency hearing loss. J. Acoust. Soc. Am. 73:961-965, 1983.

FOWLER EP. Marked deafened areas in normal ears. Arch. Otolaryngol. 8:151-155, 1928.

FOWLER EP. A method for the early detection of otosclerosis. Arch. Otolaryngol. 24:731-741, 1936.

FOWLER EP. The diagnosis of diseases of the neural mechanisms of hearing by the aid of sounds well above threshold. Am. Otol. Soc. 27:207-219, 1937.

GreEN DM, MCKey MJ, LICKLIDER JCR. Detection of a pulsed sinusoid in noise as a function of frequency. J. Acoust. Soc. Am. 31:1446-1452, 1959.

HELLMAN RP. Loudness scaling by magnitude scaling: Implications for intensity coding. In: Gescheider GA, Bolanowski SJ, (eds) Ratio Scaling of Psychological Magnitude: In Honor of the Memory of S. S. Stevens. Erlbaum Hillsdale, NJ, 1991, p. 215-228.

HELLMAN RP. Relation between the growth of loudness and highfrequency excitation. J. Acoust. Soc. Am. 96:2655-2663, 1994.

HELLMAN RP. Growth of loudness in sensorineural impairment: Experimental results and modeling implications. In: Jesteadt W, (ed) Modeling Sensorineural Hearing Loss. Erlbaum Mahwah, NJ, 1997, p. 199-212.

HeLlman RP. Cross-modality matching: A tool for measuring loudness in sensorineural impairment. Ear Hear. 20:193-213, 1999.

Hellman RP, Meiselman CH. Prediction of individual loudness exponents from cross-modality matching. J. Speech Hear. Res. 31:605-615, 1988

Hellman RP, Meiselman CH. Loudness relations for individuals 
and groups in normal and impaired hearing. J. Acoust. Soc. Am. 88:2596-2606, 1990.

Hellman RP, Meiselman CH. Rate of loudness growth for pure tones in normal and impaired hearing. J. Acoust. Soc. Am. 93:966975, 1993.

Hellman RP, Zwislocki JJ. Some factors affecting the estimation of loudness. J. Acoust. Soc. Am. 33:687-694, 1961.

HeLlman RP, ZWISLOCKI JJ. Monaural loudness function at $1000 \mathrm{cps}$ and interaural summation. J. Acoust. Soc. Am. 35:856-865, 1963.

HeLlman RP, ZWisLocki JJ. Loudness function of a 1000-cps tone in the presence of a masking noise. J. Acoust. Soc. Am. 36:1618$1627,1964$.

HICKS ML, BuUs S. Efficient across-frequency integration: Evidence from psychometric functions. J. Acoust. Soc. Am. 107:33333342, 2000.

JERGER J. Hearing tests in otologic diagnosis. ASHA 4:139-145, 1962. JEsteadT W. An adaptive procedure for subjective judgments. Percept. Psychophys. 28:85-88, 1980.

KNAuss HP. An empirical formula for the loudness of a 1000-cycle tone. J. Acoust. Soc. Am. 9:45-46, 1937.

LEviTT H. Transformed up-down methods in psychoacoustics. J. Acoust. Soc. Am. 49:467-477, 1971.

LOCHNER JPA, BURGER JF. Form of the loudness function in the presence of masking noise. J. Acoust. Soc. Am. 33:1705-1707, 1961.

MiskolCZY-FoDOR F. Relation between loudness and duration of tonal pulses. III. Response in cases of abnormal loudness function. J. Acoust. Soc. Am. 32:486-492, 1960.

Moore BC, Huss M, Vickers DA, Glasberg BR, Alcantara Ji. A test for the diagnosis of dead regions in the cochlea. Br. J. Audiol. 34:205-224, 2000.

MOORE BCJ. Cochlear Hearing Loss. Whurr London, 1998.

MoORe BCJ, GLASBERG BR. A model of loudness perception applied to cochlear hearing loss. Aud. Neurosci. 3:289-311, 1997.

Moore BCJ, Glasberg BR, Baer T. A model for the prediction of thresholds, loudness, and partial loudness J. Aud. Eng. Soc. 45:224-240, 1997.

NeEly ST, Allen JB. Relationship between the rate of growth of loudness and the intensity DL. In: Jesteadt W, (ed) Modeling Sensorineural Hearing Loss. Erlbaum Mahwah, NJ, 1997, p. 213-222.

PATUZZI RB. Otoacoustic emissions and the categorization of cochlear and retrocochlear hearing losses. Br. J. Audiol. 27:9195, 1993.

Pick G, Evans EF, Wilson JP. Frequency resolution in patients with hearing loss of cochlear origin. In: Evans EF, Wilson JP, (eds) Psychophysics and Physiology of Hearing Academic London, 1977, p. 273-281.

Pohlman AG, Kranz FW. Binaural minimum audition in a subject with ranges of deficient acuity. Soc. Exp. Biol. Med. Proc. 20:335337, 1924.

Robles L, Ruggero MA, Rich NC. Basilar membrane mechanics at the base of the chinchilla cochlea. I. Input-output functions, tuning curves, and phase responses. J. Acoust. Soc. Am. 80:13641374, 1986.
Ruggero MA, Rich NC, Recio A, Narayan SS, Robles L. Basilarmembrane responses to tones at the base of the chinchilla cochlea. J. Acoust. Soc. Am. 101:2151-2163, 1997.

SCHARF B. Critical bands. In: Tobias JV (ed) Foundations of Modern Auditory Theory, Vol. I. Academic New York, 1970, p. 157-202.

SCHARF B. Comparison of normal and impaired hearing II. Frequency analysis, speech perception. In: Ludvigsen C, Barfod J, (eds) Sensorineural Hearing Impairment and Hearing Aids, Scand. Audiol. Suppl. 6. Danavox Copenhagen, 1978a, p. 81-106.

SCHARF B. Loudness. In: Carterette EC, Friedman MP, (eds) Handbook of Perception: Vol. 4. Hearing. Academic New York, 1978b, p. 187-242.

Scharf B, Florentine M. Psychoacoustics of elementary sounds. In: Studebaker GA, Bess FH, (eds) The Vanderbilt Hearing-Aid Report. State of the Art-Research Needs. Monographs in Contemporary Audiology Upper Darby, PA, 1982, p. 3-15.

SCHARF B, Hellman RP. A model of loudness summation applied to impaired ears. J. Acoust. Soc. Am. 40:71-78, 1966.

SCHARF B, Stevens JC. The form of the loudness function near threshold. In: Proc. 3rd Int. Congr. Acoust. Elsevier Amsterdam, 1961, p. 80-82.

SCHLAUCH RS, DigIOVANNI JJ, RiEs DT. Basilar membrane nonlinearity and loudness. J. Acoust. Soc. Am. 103:2010-2020, 1998.

StEINBERG JC, GARDNER MB. The dependence of hearing impairment on sound intensity. J. Acoust. Soc. Am. 9:11-23, 1937.

STEvens SS. The measurement of loudness. J. Acoust. Soc. Am. 27:815-827, 1955

STEVENS SS. The psychophysics of sensory function. In: Rosenblith WA, (ed) Sensory Communication. MIT Cambridge, MA, 1961, p. 1-33.

Summers V, LEEK MR. Masking of tones and speech by Schroederphase harmonic complexes in normally hearing and hearingimpaired listeners. Hear. Res. 118:139-150, 1998.

VIEMEISTER NF. Psychophysical aspects of auditory intensity coding. In: Edelman GM, Gall WE, Cowan WM, (eds) Auditory Function: Neurobiological Bases of Hearing. Wiley New York, 1988.

YATES GK. The basilar membrane input-output function. In: Dallos P, Geisler CD, Matthews JM, Ruggero MA, Steele CR, (eds) The Mechanics and Biophysics of Hearing. Springer-Verlag New York, 1990, p. 106-113.

ZWICKER E. Über psychologische und methodische Grundlagen der Lautheit. Acustica 8:237-258, 1958.

ZWICKER E. Subdivision of the audible frequency range into critical bands (Frequenzgruppen). J. Acoust. Soc. Am. 248, 1961.

ZWICKER E. Über die Lautheit von ungedrosselten und gedrosselten Schallen. Acustica 13:194-211, 1963.

Zwicker E, Feldtkeller R. Das Ohr als Nachrichtenempfänger. Hirzel-Verlag Stuttgart, Germany, 1967. [Available in English translation by Müsch, H, Buus, S, Florentine, M (1999) The Ear as a Communication Receiver. Woodbury, NY, Acoust. Soc. Am.]

ZWicker E, SCHARF B. A model of loudness summation. Psychol. Rev. 72:3-26, 1965.

ZWISLOCKI JJ. Analysis of some auditory characteristics. In: Luce RD, Bush RR, Galanter E, (eds) Handbook of Mathematical Psychology. Wiley New York, 1965, p. 1-97.

Zwislocki JJ, Hellman RP. On the "psychophysical law.” J. Acoust. Soc. Am. 32:924, 1960. 